This item was submitted to Loughborough's Research Repository by the author.

Items in Figshare are protected by copyright, with all rights reserved, unless otherwise indicated.

\title{
Developing a deeper understanding of positive customer feedback
}

PLEASE CITE THE PUBLISHED VERSION

https://doi.org/10.1108/JSM-07-2016-0263

\section{PUBLISHER}

(C) Emerald

\section{VERSION}

AM (Accepted Manuscript)

\section{PUBLISHER STATEMENT}

This work is made available according to the conditions of the Creative Commons Attribution-NonCommercialNoDerivatives 4.0 International (CC BY-NC-ND 4.0) licence. Full details of this licence are available at: https://creativecommons.org/licenses/by-nc-nd/4.0/

\section{LICENCE}

CC BY-NC-ND 4.0

\section{REPOSITORY RECORD}

Nasr, Linda, Jamie Burton, and Thorsten Gruber. 2019. “Developing a Deeper Understanding of Positive Customer Feedback". figshare. https://hdl.handle.net/2134/26445. 


\section{Developing a deeper understanding of positive customer feedback}

\begin{tabular}{|r|l|}
\hline Journal: & Journal of Services Marketing \\
\hline Manuscript ID & JSM-07-2016-0263.R2 \\
\hline Manuscript Type: & Article \\
\hline Keywords: & $\begin{array}{l}\text { Service encounter, Positive Customer Feedback, Front-line Employees, } \\
\text { Laddering, ZMET }\end{array}$ \\
\hline \multicolumn{2}{|c}{} \\
\hline
\end{tabular}

\section{SCHOLARONE ${ }^{\text {m }}$ \\ Manuscripts}




\title{
Developing a Deeper Understanding of Positive Customer Feedback
}

\author{
Structured Abstract: \\ Purpose: The purpose of this paper is to highlight the importance and extend the understanding \\ of the under researched concept of personal Positive Customer Feedback (PCF). By comparing \\ and contrasting Front-Line Employees' (FLEs) and customers' perspectives, this study aims to \\ develop a deeper understanding of the main elements, characteristics of PCF, its various impacts, \\ and the perceived importance of this phenomenon for both parties.
}

Design/methodology/approach: An exploratory research study was conducted using a novel integrated methodological approach combining two well-established qualitative techniques: structured Laddering interviews and various elements of the Zaltman Metaphor Elicitation Technique (ZMET). In total, personal interviews with 40 participants consisting of 20 customers and 20 FLEs were conducted.

Findings: This study conceptualizes personal PCF in the service literature by identifying the various PCF elements and characteristics. We extend PCF understanding beyond what the current literature shows (i.e. gratitude, compliments) by identifying nine characteristics of PCF. This study also proposes a number of impacts on both customers and FLEs. While both customers and FLEs have a similar understanding of the various elements and characteristics of PCF, the significance of the various elements and the subsequent impacts vary between the two groups. Finally, three key themes in PCF handling that help position PCF within the extant customer management literature are identified and discussed.

Research limitations/implications: This study contributes to a well-rounded understanding of customer feedback by counter-balancing the prevailing focus on customer complaining behaviour and proposing a complimentary look at the positive valence of personal feedback. It also provides managerial implications concerning the management of positive service encounters, an emerging topic within service research. 
Originality/value: This multidisciplinary study is the first to extend the understanding of personal PCF by comparing and contrasting customers' and FLEs' perspectives. The findings of this study highlight the need to explore the positive side of service interactions in order to create positive service experiences.

Key Words: Service Encounter, Positive Customer Feedback, Front-line Employees, Laddering, ZMET.

Paper Type: Research Paper 


\section{Developing a Deeper Understanding of Positive Customer Feedback}

\section{Introduction}

Considerable research has recognized the various advantages of receiving, analysing, and managing customer feedback (Ordenes et al., 2014). However, current service research seems to be mostly "listening" to the negative voices. For decades, driven by the goal to fix problems, such that costs (like negative word-of-mouth, customer switching behaviour, and lost turnover) can be managed and minimized, service researchers were primarily concerned with negative customer feedback. Thus, the main focus was on customer complaints, dysfunctional customer behaviour, and customer rage (e.g., Daunt and Harris, 2014; Patterson et al., 2016).

Although these studies advanced the area of customer feedback management, service researchers have paid less attention to human appreciation (Nasr et al., 2014). Nevertheless, this notion represents a fundamental component of social relationships (Howells and Cumming, 2012) and, accordingly, has been an essential ingredient to theories concerning social relationships and reciprocal behaviours across a variety of disciplines (Bartlett and DeSteno, 2006). For example, it has been found that appreciation and gratitude help with coping with stressful situations, strengthening social relationships, and increasing positive emotions (Grant and Gino, 2010). The limited research around appreciation within service research is surprising, given that service encounters are, in their essence, social interactions involving service customers and providers. Additionally, service companies are continually striving to decrease stress levels within service encounters (Bailey et al., 2001), strengthen their relationships with customers (Verhoef, 2003), and increase customers' positive emotions as a way to build positive customer experiences (Gentile et al., 2007).

We suggest that customer feedback is an essential medium for the delivery of customer appreciation and the sharing of positive emotions, which can have crucial positive implications on customers, Front-Line Employees (FLEs), and companies. Given that most of the customer feedback is delivered in person to FLEs during service encounters (Wirtz et al., 2010), a deeper understanding of personal Positive Customer Feedback (PCF) from the perspective of both 
customers and FLEs is needed. Given the importance of customer participation in creating their own experiences (Palmer, 2010) and considering the established benefits of positive feedback for the giver and recipient, makes the need to consider PCF in greater depth especially notable.

In this respect, a number of research gaps are identified: first, previous research is biased towards negative customer feedback (Erickson and Ecktich, 2001). Even though there is a substantial amount of research that looked into the various elements and dynamics within service encounters in general (e.g., Bitner et al., 1990; Lariviere et al., 2017); and customer-employee personal interactions in particular (e.g. Pugh, 2001; Delcourt et al., 2017), only a limited number of studies specifically looked at the positive valence of customer feedback (e.g., Kraft and Martin, 2001; Robinson and Berl, 1979) while proposing more questions than answers and failing to explain the various elements and characteristics of PCF. Second, although in a recent study the impact of PCF on well-being was established (Nasr et al., 2014), the operationalisation of this impact and its importance remained unclear. Third, some previous studies offer a fragmented overview of PCF by collecting data from employees and managers while failing to include the customer's perspective (e.g., Erickson and Ecktich, 2001). Finally, previous research discusses contrasting and sometimes contradicting impacts of PCF (e.g., Nasr et al., 2015). Thus, research on PCF fails to give a coherent and in-depth understanding of this important phenomenon.

This study aims to fill these gaps by investigating, through comparing and contrasting, customers' and employees' perceptions of personal PCF, the main elements and characteristics of PCF, its various impacts, and the significance of this phenomenon for both parties. By looking at both customers' and employees' perspectives, this study helps identify whether customers' understanding of what constitutes personal PCF differs from what contact employees perceive. Moreover, it helps recognize the impacts associated with personal PCF for both parties involved in the service encounter. Accordingly, this study is impactful in a number of ways. First, we contribute to the advancement of research by addressing topics that many researchers have identified as crucial for the future of service research. In particular, we respond to the needs for more studies around the role of positive experiences and positive relationships (Gable and Haidt, 2005) by exploring the overlooked concept of PCF. Additionally, we provide an in-depth understanding of a major phenomenon taking place during a service encounter (Kunz and Hogreve, 2011) by looking at both FLEs' and customers' perspectives of personal PCF. We 
subsequently dissect personal PCF to understand its main elements and characteristics, its various impacts, and its importance for both parties. It is hoped that this study will unfold an area of research and methodology which will generate considerable benefits for researchers interested in stretching the boundaries of service encounter and customer feedback management research. Finally, by comparing customers' and employees' perspectives, it is contended that this study has vital managerial implications as it increases employees' and managers' awareness and understanding of positive customer communications and their potential outcomes, which are crucial for successful employee management, customer relationship building, and service experience enhancement.

This paper begins with an overview of the role and importance of customer feedback and the need to focus on PCF within service. We, then, present the research questions and the novel integrated methodological approach consisting of combined structured laddering interviews and two key elements of the Zaltman Metaphor Elicitation Technique (ZMET); the visual projective technique and unstructured in-depth questions (Zaltman, 1997). Subsequently, we describe the chosen data analysis techniques followed by a discussion of the results. Finally, we propose managerial implications and outline limitations and directions for further research.

\section{Literature Review \\ Customer feedback}

Identified as a form of customer engagement (Van Doorn et al., 2010), customer feedback is defined as customer communication concerning goods and (customer) service (Erickson and Ecktich, 2001). Though customer engagement is a somehow new concept (Brodie et al., 2011), customer feedback research has been conducted much longer and in greater depth.

According to Witell et al. (2011), customer feedback can be either structured or unstructured. Structured feedback takes the form of quantitative surveys, while unstructured feedback comes through telephone calls, e-mails, and social media, thus, giving the customers more flexibility to describe their experiences in more details. Ordenes et al. (2014) present another categorization of customer feedback and propose that "customer feedback can be classified as 'explicit or implicit' 
depending on whether the customers consciously or unconsciously provide a third party with information about their experiences" (p. 280). Traditional channels for explicit customer feedback collection include platforms such as surveys, e-mail, online reviews, while organizations collect implicit feedback, when tracking customer-determined actions, through measuring activities such as; eye tracking, reading time, number of pages scrolled, and number of clicks obtained in a web document (Poblete and Baeza-Yates, 2008). Finally, Sampson considers the "initiator" of customer feedback as the basis of his categorization and proposes that customer feedback could be either active or passive, also referred to as solicited and unsolicited feedback (e.g., Wirtz and Tomlin, 2000). Companies use active feedback collection tools (or solicited feedback) to invite customers to express feedback, for example, through surveys, focus groups, and interviews, thus the initiator of this feedback is the company. In contrast, passive feedback collection (or unsolicited customer feedback) relies on the customers' own desire and will to express their experiences (Mattila and Wirtz, 2004). Witell et al. (2011) argue that unstructured and unsolicited feedback assigns more active roles to customers as they engage in providing organizations with richer information about their experiences. Two types of unsolicited customer feedback are identified: interpersonal communication to other people (e.g., WOM, EWOM) and communication to firms (Day and Landon, 1977).

Although organizations traditionally focused on solicited feedback, a substantial amount of research was conducted on the importance and effects of WOM (e.g., Litvin et al., 2008). Moreover, with technological advances presenting customers with new channels and platforms through which they can provide feedback (Witell et al., 2011) and the growing importance of big data and social media content, unsolicited feedback became the central focus of many researchers and organizations (Ordenes et al., 2014). Nevertheless, research suggests that the majority of the unsolicited customer feedback communicated to service firms is addressed in person to FLEs rather than through other channels (Wirtz et al., 2010), which makes the customer and the FLE key sources of information for organizations through the centrality and frequency of their interactions (Voss et al., 2004). Finally, unsolicited customer feedback, could be directly given to the FLE through verbal interaction or indirectly through tipping and other symbolic actions (Voss et al., 2004). 
As evidenced by the various identified categorizations, customer feedback has been widely studied in the service literature. This is mainly due to the strategic position of customer feedback within companies' operations. For example, customer feedback management outcomes include assistance in performance measurement and facilitation of organizational learning (Caemmerer and Wilson, 2010) by gaining insights for new product and service development (Fundin and Bergman, 2003). Moreover, feedback management leads to improvement in decision making and service quality (Wirtz et al., 2010), generating competitive advantage (Lusch et al., 2007), and building stronger customer relationships (Frow and Payne, 2009). Finally, the analysis of customer feedback leads to an improved customer experience by designing a more accurate, customer-focused service blueprint (Ordenes et al., 2014).

\section{Positive customer feedback}

Despite the substantial work done in the area of customer feedback management, most of the research conducted so far focuses on customer complaints and dissatisfaction. The customer complaining field was pioneered by Best and Andreasen (1977) and thereafter has been the emphasis of many scholars (e.g., Gruber et al., 2008; Henneberg et al., 2015), leaving the various manifestation of PCF quasi-marginalized (Nasr et al., 2014). We do not deny the merits of these robust studies in advancing the area of customer feedback management; where both valences of customer feedback have been acknowledged and considered (e.g., Ordenes et al., 2014), but we do propose a complimentary in-depth look at personal PCF.

Our literature review identified a small number of studies conducted on PCF. Robinson and Berl (1979) were among the pioneers to investigate personal PCF. Their particular focus was on a particular element and characteristic of personal PCF; “customer compliments". The authors made the first effort to study customer compliments, recognizing that customer compliments seem to be more frequent than customer complaints. However, many companies do not have established systems to capture them. In addition to customer compliments, two other elements and characteristics of personal PCF are discussed in the literature: customer empathy and customer gratitude. Customer empathy is defined as customer's apprehension of and reaction to an employee's thoughts, feelings, and intentions during a service interaction (Wieseke et al., 2012). Gratitude, on the other hand, has been recently rediscovered as a research priority within 
Positive Psychology (Young and Hutchinson, 2012) and accordingly has been studied by various social scientists (Howells and Cumming, 2012). Within service research, customer gratitude has been briefly studied through the lens of relationship marketing (Palmatier et al., 2009).

Kraft and Martin (2001) criticized the current practices of focusing solely on studying customer complaining behaviour and called for research considering the other side "of the same coin" ( $p$. 11). They proposed that encouraging, recognizing, understanding, and acting on positive feedback is a strategic step for every service organization because of its potential strategic impact. In this regards, Baron and Warnaby (2011) found that soliciting positive feedback produces valuable information for improving services. Furthermore, personal PCF contributes to the creation of more productive and happier FLEs (Nasr et al., 2014). Similarly, customer empathy was found to act as a qualifier of social interaction by nurturing alignment of feelings and thoughts and creating smooth and harmonious interactions (Gremler and Gwinner, 2008). Moreover, research shows that empathy could foster successful interactions and mitigate the effects of negative experiences in service interaction (Wieseke et al., 2012). Equally, customer gratitude was found to create long-lasting performance benefits based on gratitude-related reciprocal behaviors. In particular, research shows that customer gratitude is a fundamental component of buyer-seller relationships and that it plays a vital role in realizing how relationship marketing investments increase purchase intentions, sales growth, and share of wallet (Palmatier et al., 2009).

In addition, Erickson and Ecktich (2001) studied the importance of PCF for customers and found that complimenting customers are already predisposed to relationship building since they are engaged enough to invest time and energy in communicating the positive feedback to the employee. Similarly, Heskett et al. (1994) found that complimenting customers are the most motivated, vocal, and satisfied ones; therefore, they should be the obvious choice for long-term relationship building and customer engagement. On the other hand, Eisenberger et al. (1990) studied the importance of PCF for FLEs and found that it satisfies the employee's social need for approval, affiliation, and esteem. Nevertheless, these studies are limited and raise a number of unanswered but crucial questions, in particular, regarding the various personal PCF elements and characteristics, impacts and perceived importance. 


\section{Research Objective}

In light of the limited knowledge in the area of PCF, it is vital to deepen our understanding of PCF in a service setting. Previous research studies fail to answer the following questions: How do customers and FLEs perceive personal PCF? What are the main characteristics and elements of personal PCF as identified by customers and FLEs? What does personal PCF mean to customers and FLEs? Are there inconsistencies in personal PCF perceptions between customers and FLEs? What are the impacts of personal PCF on customers and FLEs? Why is personal PCF important to both customers and FLEs? Therefore, the objective of this study is to expand the understanding of unsolicited personal PCF, having the FLE as subject and recipient, by using the perspectives of both parties involved in a service encounter. For this purpose, we aim to compare and contrast customers' and employees' perceptions of personal PCF elements and characteristics, its various impacts, and the significance of this phenomenon for both parties. Thus, this study will provide a much needed conceptualization and deeper understanding of PCF.

\section{Integrated Methodological Approach}

An exploratory approach was selected in order to gain a deeper understanding (Malhotra and Birks, 2006) of the understudied PCF phenomena. For this purpose, qualitative techniques were adopted since they are capable of capturing the complexities of and extracting detail information about sensitive subject areas and phenomenon (Keegan, 2009). Similarly, a qualitative approach is suitable when limited theory exists to explain the relationships between the concepts under study (Altinay et al., 2014). We adopted an integrated hybrid methodology consisting of wellknown qualitative methods such as laddering (Reynolds and Gutman, 1988), combined with elements of the Zaltman Metaphor Elicitation Technique (ZMET) (Zaltman, 1997).

\section{Laddering}

Laddering refers to a one-on-one, in-depth interviewing technique used to gain a deeper understanding of the individual deep reasoning regarding a specific topic (Zaltman, 1997). Laddering was selected because it is a well-established technique for exploratory research. In particular, laddering helps discover what a certain phenomenon (in this study PCF) means to 
individuals by using probing questions to gain a better acumen of the individual's deep reasoning vis-à-vis a particular topic (Zaltman, 1997). This technique is grounded in the means-end approach that draws on insights from motivation and cognitive psychology, which state that the values or desirable end-states are the key motivators of consumers' choice models (Gutman, 1982). As such, the attributes of things are "means" to reach higher level consequences (psychological or functional), which, in turn, are means to achieve an ultimate value ("ends") (Olson and Reynolds, 2001). Therefore, laddering usually involves personal semi-standardized in-depth interviews where probing questions are used to uncover Attribute-Consequence-Value chains.

In this study, through the laddering interviews, we aim to uncover the Attributes (A), Consequences (C) and perceived Values (V) associated with personal PCF occurrence.

- Attributes (A) are usually tangible and intangible characteristics of a good, a service, or an individual. In this study, Attributes (A) are customers' and employees' perceptions of the main elements and characteristics of personal PCF.

- Consequences (C) usually describe why a certain attribute is important to the individual. In this study, Consequences (C) are the impacts of personal PCF on FLEs and customers.

- Values (V) are universal life goals, and as described by Rokeach (1973), they are the most personal consequences people are aiming for in their lives. In this study, Values (V) reflect the perceived importance that customers and FLEs associate with personal PCF.

Therefore, Attributes (A) - Consequences (C) - Values (V) are laddering specific terms, while elements and characteristics, impacts and perceived importance are study specific terms. Taken together, the generated linkages between the Attributes (elements and characteristics), Consequences (impacts) and Values (importance) of PCF were then translated into visual linkages (means-end chains), displaying detailed relationships between $\mathrm{A}-\mathrm{C}-\mathrm{V}$ and referred to as Hierarchical Value Maps (HVM) (Reynolds and Gutman, 1988).

\section{Zaltman Metaphor Elicitation Technique}

Previous research shows that customers and employees might feel embarrassed or reluctant to express their sincere feelings regarding positive feedback, as giving (Martinuzzi, 2009) or 
receiving praise (Nasr et al., 2015) could be intimidating. Therefore, in order to address this possible issue, known as "blocking" (Reynolds and Gutman, 1988), we adopted the approach used by Barnett et al. (2014) and integrated the visual projection elements of the ZMET into laddering. In addition, in order to acutely understand the different perceptions of the two parties, the in-depth unstructured questions component of the ZMET technique was also employed (Zaltman and Higie, 1993).

ZMET is a hybrid methodology that incorporates the visual projection technique, in-depth personal interviews, and a range of qualitative data-processing tools (Lee et al., 2003). It has been used as an academic research tool to enhance the understanding of customer thinking and behaviour (Coulter and Zaltman, 1994). Our study utilized a combination of two key ZMET elements: visual projective technique and in-depth personal interviews.

The visual projective technique of ZMET is built on the premise that research tools need to further emphasize non-verbal communication (Zaltman, 1997). ZMET advocates that most people find it easier to express themselves through images rather than words. Therefore, at the heart of the ZMET approach is the idea of "knowledge representation" or "metaphors" (Coulter and Zaltman, 1994). These representations are prompted through the usage of projective techniques by asking the participants to present and describe images that reflect their perceptions of a particular issue. The aim is to help the participants express what they find difficult to articulate.

In addition, within ZMET, there is a need to ask the respondents some unstructured and in-depth questions. In this respect, the researcher used reflexive interviewing techniques such as restating informants comments and summarizing to ensure a full understanding (Roger and Farson, 1984).

\section{Integrating both methods}

In this study, ZMET elements were incorporated into the laddering technique, by first implementing the visual projective technique, which forms the basis of the structured laddering interview, and second by asking in-depth, unstructured questions regarding aspects of PCF that the structured laddering questions failed to explain. This integration of methods helps to overcome the identified phenomenon of "blocking" (Barnett et al., 2014), by making the 
participants reflect about their thoughts and feeling in advance of the interview and accordingly projecting them into images of their choice. It also triggers thoughts and feelings in the participants and generates meanings that otherwise might not be extracted in a face-to-face or focus group interview. Finally, combining laddering and ZMET elements allows the researcher to look at the data in a deeper and varied way (Christensen and Olson, 2002).

\section{Data Collection}

Sample size and characteristics

According to Reynolds et al. (2001), the minimum sample size required for conducting laddering research is 20 participants per subgroup as it can give a full range of attributes, consequences, and values. Subsequently, personal interviews were conducted with 40 participants $(20$ service customers and 20 FLEs) working in different service industries.

Snowball sampling was used as a non-probability sampling technique. It consists of asking the recruited participants to recommend further participants who share the required characteristics to be eligible to take part in the study (Malhotra and Birks, 2006). Snowball sampling is a suitable technique for exploratory research, and it has been used in similar service research (e.g., Groth et al., 2009). We started with the customer subgroup by approaching and inviting two random customers of a local coffee shop to participate. Afterwards we asked for referrals (acquaintances, friends and family members who qualify to serve as customer participants in this study) and the chain referral, via the snowballing technique, of the customer subgroup began. Customer participants were customers of various service industries including retail, hospitality, and tourism. Similarly, the management of a local service company, who offered help with the research, selected two FLE respondents. After interviewing these two FLEs, we asked them for referrals (acquaintances, friends and family members who qualify to serve as FLE participants in this study). Afterwards the chain referral, via the snowballing technique, of the FLE subgroup began. The inclusion criteria for employee participants was to have working experience as FLEs in a service industry. In order to match the expertise of the customers, FLEs working in the hospitality, retail, and tourism industries were prioritized (e.g., sales coordinator, barista, sales 
representative, and receptionist). We did not have an open call for participation but rather emailed those potential participants who verbally expressed a desire to participate (either when the researcher(s) approached them in person or through the referring person). Most of the approached participants agreed to participate and arrangements were made to set the interview time and place around their schedule and preferences. The characteristics of customer and FLE samples are summarized in Table 1.

Insert Table 1 about here

\section{Data collection process}

In order to answer the research questions of this study, data were collected in two stages:

Stage 1: Image collection

Adopting the ZMET premise, our 40 participants (20 service customers and 20 FLEs working in different service industries) were asked, via email, to find up to five images that represented their thoughts and feelings about communicating PCF during a service encounter. We did not instruct the participants about particular meanings or manifestations of unsolicited PCF, this was left to them to decide. The participants were given up to seven days to collect the images and were instructed to email the images to the interviewer prior to the interview as per Zaltman's (1997) recommendation. We instructed the participants to find images through regular web search or by taking the images themselves with a camera. We did not give any further instructions, in order not to bias the participants. The average number of submitted images per participant was 4.8 $(\mathrm{N}=97)$ for the customer subgroup and $4.4(\mathrm{~N}=88)$ for the FLE subgroup. Accordingly, a total of 185 images were collected from the 40 participants.

Stage 2: Personal interviews

The 40 participants (20 service customers and 20 FLEs) were instructed to rank/sort the collected images starting with what they felt was the most meaningful picture. They were subsequently 
asked to briefly describe the picture and its meaning. This sorting task is one of the core steps in implementing ZMET (Zaltman, 1997). Accordingly, the participants were asked to explain why they chose a particular picture. This approach helped overcome the possible issue of "blocking" (Barnett et al., 2014). Instead of starting the interview by asking "what are the attributes of PCF?" which might put the respondents in an uncomfortable or reluctant position (Martinuzzi, 2009; Nasr et al., 2015), the participants described the images and narrated stories associated with the selected pictures. As the topic is positive, most of the images were bright, colourful, and positive in nature and accordingly put the respondents in an optimistic mood, which resulted in them feeling more comfortable and at ease. As an example, the following figure shows two images that respondents selected.

Insert Figure 1 about here

Based on the given answers, the researcher either "ladder(ed) down" by asking questions that help uncover the PCF attributes or "ladder(ed) up" to uncover the consequences and values associated with PCF giving/receiving. Table 2 represents a simplified process of laddering up and laddering down by using probing questions to both customers and FLE participants.

Insert Table 2 about here

The purpose of questioning is to reveal structural relationships between the attributes of PCF, the consequences of these attributes, and the personal values and/or goals that these consequences reinforce. Accordingly, the interviewer continuously asked: "Why is attribute/ consequence/ value 'xyz' important to you?" serving as the starting point for further questioning based on the received answer about the particular described encounter. In order to reach the higher level of consequences and values, the interviewer asked the question, "How does that make you feel?" as per Reynolds et al.'s (2001) recommendations. The structured questioning continued until 
participants were not able or willing to give an answer or until they were giving repetitive or circular answers or had reached the value level (i.e. the ultimate importance of this phenomenon). Once all the images were discussed, participants were also asked to describe any missing images which they were unable to obtain and explain their relevance (Zaltman, 1997).

Finally, some unstructured, in-depth questions were asked to clarify any ambiguity resulting from the laddering procedures and to gain deeper understanding of the identified attributes, consequences, and values. After each interview, participants were asked to review the ladders that the researcher noted for confirmation/validation and to clarify any possible misunderstanding. Each interview was recorded for verbatim transcription employed in the data analysis and lasted between 40 and 70 minutes.

\section{Data Analysis}

Following the recommendation of Reynolds and Gutman (1988), the data were analysed in three stages. At first, content analysis was used in order to code the data from the interviews. Content analysis is a systematic technique that aims to analyse the informational content of textual data (Forman and Damschroder, 2008). Phrases from the interviews were categorized as either an attribute, consequence, or value (the "ladder"). During this first phase, categories were developed to group together comparable phrases and data points across participants. An iterative process of coding was used, where data were split, combined, and (re)-grouped into meaningful categories in line with content analysis techniques (Corbin and Strauss, 2008). Data with identical meanings were grouped into aggregated categories derived from the participants' answers or from the literature review (Krippendorff, 2004).

A systematic coding approach was adopted. First, the researcher who conducted the interviews carried out the preliminary coding of the data, taking into account the contextual information related to each respondent (such as the collected images, the responses to the unstructured questions, personal experiences and stories, demographics, etc.) when assigning meanings to the answers as suggested by Grunert and Grunert (1995). Subsequently, two experienced coders conducted separate evaluations of the coding process (conducted by the first coder) by 
independently going manually through all the codes and ladders. For the manual coding, each coder annotated his or her own version of the Excel file of codes. These two independent coders then discussed and agreed on the codes between each other. They subsequently delivered a joint coding report. Finally, a third independent coder acted as a third-party judge by looking at the disagreements between the original coder and the joint recommendations made by the two experienced coders. The results were compared and measured by using Perreault and Leigh's 'index of reliability' (1989) in order to check the reliability of the coding. This index, which is particularly suitable in cases where two or more coders are used, has been recommended by previous researchers (Iacobucci, 2001). The 'index of reliability' in this study was 0,85; suggesting that the coding was reliable (Perreault and Leigh, 1989). The third independent coder made the final decision regarding any identified inconsistencies, as per the recommendations of Reynolds and Phillips (2008). Employing a number of independent coders ensured consistency in coding and allowed for inter-coder reliability testing, which is particularly crucial to ensure the reliability and validity of the analysis (Hennink et al., 2011).

Four tables were generated listing the PCF attributes (Table 3), the consequences for customers (Table 4) and employees (Table 5), and the values imperative for both parties (Table 6) concerning PCF. Each table succinctly describes each identified construct and states the number of times each concept was mentioned. The codes are listed alphabetically.

Insert Tables 3, 4, and 5 about here

Schwartz's (1994) Universal Values list was used to code the end value categories as it provides an overview of generally held values and has been effectively used in previous laddering studies (e.g., Barnett et al., 2014; Henneberg et al., 2015). Schwartz (1994) defines values as "desirable trans-situational goals, varying in importance that serve as guiding principles in the life of a person or other social entity" (p. 21). 
Insert Table 6 about here

The second stage of the analysis consisted of coding the sequences of A-C-Vs (ladders) aggregated across subjects using the decision-support software program LADDERMAP (Gengler and Reynolds, 1993) to generate implication matrices, for each subgroup, that express the number of associations between the identified attributes, consequences, and values. According to Deeter-Schmelz et al. (2002), the implication matrix acts as a bridge between the qualitative and quantitative element of the laddering technique by generating the number of times one code leads to another. These implication matrices depict the amount of direct and indirect links that a particular concept has with another (Deeter-Schmelz et al., 2002). Direct relationship represents a connection where a concept (attribute/consequence) is directly connected to another concept (attribute/consequence) in the same ladder, while indirect relationship represents a connection where a concept (attribute/consequence) is connected to another (attribute/consequence) but with another concept (attribute/consequence) in between (Reynolds and Gutman, 1988). A total of 629 ladders were entered into LADDERMAP, divided as follows: 324 ladders from customer subgroup and 305 ladders from FLE subgroup.

The third stage consisted of generating the Hierarchical Value Maps (HVM), for each subgroup, with the data from the corresponding implication matrices. A HVM is defined as "a graphical representation of a set of means-end chains which can be thought of as an aggregate cognitive structure map" (Gengler et al., 1995, p. 245). The map's main role is to summarize the findings of the laddering interviews analysis (Claeys et al., 1995). Therefore, the output is in the form of visual linkages indicating methodical relationships between A-C-Vs. Each map consists of several nodes, which represent the most mentioned A-C-Vs connected with lines expressing the linkages between them. Each map depicts three levels representing the attributes (first level or bottom of the map), consequences (second level or middle of the map) and values (third level or top of the map). Gengler et al. (1995) state that the first (bottom) level of the map is "somewhat cluttered and crowded" (p. 252) due to the normally larger number of identified attributes during the laddering interview. 
The size of each node (circle) represents the frequency of mentioning the concept by the participants (identified in stage 2 through the implication matrix). Therefore, the most often mentioned concept is set to receive the area of the circle to a defined maximum level. Accordingly, the circles of the other concepts are "computed proportionally to that value, based on the relative frequency of mentioning that concept" (Gengler et al., 1995, p. 253). The thickness of the lines connecting the various nodes (circles) represents the relative frequency of association between the concepts (identified in stage 2 through the implication matrix) and therefore depicts the strength of the relationship between these concepts. Therefore, a maximum line width is set first; representing the relationship between the two most strongly associated concepts. Accordingly, all the other line widths are scaled to this maximum value. By following this procedure, the reader of the map can easily depict the (1) number of times participants mentioned each concept, (2) the relationship between the concepts and (3) the strength of the relationship; i.e. strongly related concepts (connected through thick lines) versus weakly related concepts (connected through thin lines).

It is important to mention that the HVM does not have to show all the implications and connections generated through the implication matrix. In order to generate these maps, the researchers agreed on a "cut-off" level, which is used to make the maps interpretable while keeping a balance between detail and interpretability (Christensen and Olson, 2002), and data retention and reduction (Gengler et al., 1995). For example, a "cut-off" level of 1 will generate a map that includes every connection between concepts mentioned by the participants. The downside to this cut-off level is that the generated map is "unintelligible" (Christensen and Olson, 2002, p. 484). On the other hand, if the chosen "cut-off" level is too high, many linkages will disappear and the map will become not interesting. By using LADDERMAP, we were able to test the different cut-off levels in order to generate maps that are meaningful and interpretable. Accordingly, we identified consensus maps (Figure 2 and 3) at a cut-off level of 4, meaning that the participants had to mention the linkages between concepts at least 4 times for them to be included in the map. A cut-off level of 4 represents on average $60 \%$ of the data.

ZMET elements additional analysis 
ZMET elements help gain a deeper understanding of the constructs elicited through traditional laddering probes. In this respect, the collected images and content analysis of the interview transcripts helped identify a number of relevant themes. We adopted a similar approach to Lee et al. (2003), where the step of deep metaphor investigation was replaced by conceptualization of the thematic categories from the data. The typical ZMET approach to developing deep metaphors does not take into account previous theories and research advancement (Lee et al., 2003). Accordingly, creating abstractions of the thematic categories without reference to findings of the laddering interviews would limit the understanding of PCF. This would accordingly contradict one of the purposes of incorporating ZMET into this study. Therefore, the collected images were reviewed and all transcripts were closely read and the key concepts related to the laddering analysis were highlighted. Subsequently, similarities, differences and/or relationships between the concepts that help understand PCF phenomenon in greater depth and beyond the HVMs, were thoroughly searched (Giorgi, 1989). In particular, we used a similar approach to Altinay et al. (2014) were we first worked on identifying the major themes, using the participant's own language, through open coding (Corbin and Strauss, 2008) to generate the first-order concepts. Then, we used axial coding to introduce our own interpretations that helped us understand PCF phenomenon in greater depth based on the knowledge gained from the HVMs, this process helped us generate second-order themes. Finally, we grouped the second-order themes into aggregate dimensions that gave an overall overview of PCF that goes beyond the findings of the HVM. Based on this additional analysis, empirically grounded key themes were identified.

\section{Results and Discussion \\ Customer perceptions of PCF}

Figure 2 shows the HVM that graphically presents customer perceptions of PCF attributes (characteristics and elements), consequences (impacts), and values (importance).

Insert Figure 2 about here 
The HVM shows a complex structure. The most important PCF attribute is "Acknowledgement" (mentioned 16 times). In a service encounter, customers tend to admit the good service received without going further or investing extra efforts in communicating their satisfaction. This appears to be the most direct and common way for customers to express personal PCF to FLEs. This finding extends Jones et al.'s study (2015), who argue that not all customers are keen on relationship building with employees, by showing that engaging in a positive conversation or small talks is not a guarantee of long term relationship building intentions. Acknowledging a good service makes the customer feel comfortable and at ease in a service encounter ("Feeling comfortable" mentioned 17 times). Interestingly, the consequence of "Feeling comfortable", is linked to all the attributes (except "Encouragement"). Thus, the strong desire to feel comfortable could be triggering customers to express various PCFs.

By aiming to feel comfortable and at ease in a service encounter, customers indirectly experience positive emotions ("Feeling enthusiastic" mentioned 19 times and "Feeling altruistic" mentioned 20 times). Wieseke et al. (2012) found that "Feeling altruistic" or experiencing customer empathy, defined as customer's apprehension of and reaction to an employee's thoughts, feelings, and intentions during a service interaction, can act as a qualifier of social interactions, nurturing alignment of feelings and thoughts and creating smooth, harmonious interactions. In service research, empirical studies on empathy in employee-customer interactions are scarce (Weißhaar and Huber, 2016) with the majority of prior research studying the impact of employee empathy on customers (e.g. Zeithaml et al.,1996). In this study, we extend this notion, but focusing on the empathy experienced by customers and linking it to well-being outcomes. These positive emotions are indicators of enhanced well-being for customers as a result of PCF giving (Forgeard et al., 2011). Feeling altruistic is also important, as it was found that experiencing empathic feelings also fosters successful interactions and mitigates the effects of negative experiences in service interaction (Wieseke et al., 2012). Consequently, "Feeling altruistic" is linked to the most important values of "Security" (mentioned 20 times) and "Universalism" (mentioned 18 times). Thus, customers need to feel secure and strive for stability, risk reduction and harmony during a service encounter, and aim to maintain the stability of relationships they have ("Security") by being empathetic, while showing care about the well-being of others 
("Universalism"). In this respect, they also care about the well-being of those who they build a relationship with ("Relationship" mentioned 17 times). Thus, a common way for customers to achieve security is by building quality relationships with FLEs. This comes in accordance with Berry (1995) who found that risk reduction is a key outcome of service provider relationships. Nevertheless, he mainly focused on the role of companies in reducing customer risk and fostering the security feeling. We extend this notion by proposing that customers are active actors in the process and their positive feedback could be a major contributor to reducing their perceived risk.

Another reason customers express PCF is to feel in control (mentioned 15 times) of the encounter as a way to express their own power (also mentioned 15 times) and enhance their security. Our study supports that the perception of having control reinforces customers' security values (Kania and Gruber, 2013). Bitran and Hoech (1990) advocate that customers' perceived control is an important dimension of a successful service experience. Thus, we extend previous findings by proposing that the highly valued feeling of security is multidimensional and is strongly triggered by the experienced empathetic feeling, the relationship customers build with FLEs, and the control feeling they experience during a service encounter.

The second most important PCF attribute is "Connection" (mentioned 15 times). Customers tend to want to create a personal bond by exchanging feelings of care and friendliness, which might help building personal connections with FLEs. Hennig-Thurau et al. (2006) found that connection and rapport building are the main drivers for customer satisfaction. We extend this finding by showing that connection and rapport building could be triggered by customers themselves when they give PCF to employees. Therefore, it is not the sole role of the employee to foster rapport building. This attribute is also linked to consequences of "Feeling in control" and "Feeling comfortable" (each mentioned 17 times).

Interestingly, "Connection", "Loyalty" (both mentioned 14 times) and "Sensory expressiveness" (mentioned 12 times) have strong connections with the consequence of "Feeling comfortable". This could be explained by the notion that these characteristics of PCF are more behavioural and personal in nature while "Acknowledgement" and "Gratitude" (mentioned 7 times) are verbal and more formal. Thus, it might be that customers feel more comfortable when the employee 
understands their positive behaviour, enabling them to avoid having to express positive feedback verbally.

\section{FLE perceptions of PCF}

Figure 3 shows the hierarchical value map that graphically presents FLE perceptions of PCF attributes (characteristics and elements), consequences (impacts), and values (importance).

Insert Figure 3 about here

According to FLEs, the most important PCF attributes are "Acknowledgement" and "Encouragement" (both mentioned 16 times). Both attributes have a strong relationship with the most important consequence of "Feeling enthusiastic" (mentioned 20 times). Therefore, the main consequence for FLEs is the experience of positive emotions and feelings which is indirectly linked to a number of consequences including: Feeling responsible (mentioned 11 times), Relationship (mentioned 13 times), Motivation (mentioned 12 times), Job satisfaction (mentioned 14 times), and Spillover (mentioned 13 times). These findings supplement Nasr et al.'s (2014) research, which argues that PCF has a positive impact on FLE well-being, by uncovering a number of personal and work related consequences. Moreover, FLEs confirmed that the impact of PCF and the positive emotions experienced have a much wider impact that goes beyond the particular service encounter (through the strong connection between "Feeling enthusiastic" and "Spillover"). This finding supports further transdisciplinary research conducted in the field of psychology by Rodríguez-Muñoz et al. (2014) who found that an individual's work engagement and resulting happiness would spill over to their home domain, by increasing the happiness level of their family members, which alternatively increases the employee overall happiness. This major finding explains why the consequence "Spillover" is linked to one of the most important values of FLEs: "Benevolence" (mentioned 16 times) since FLEs care about the preservation and enhancement of the welfare of people with whom they are in frequent personal contact (i.e. family and friends). 
The next most important consequences for FLEs resulting from personal PCF are "Self-efficacy" and "Enhanced self-image" (both mentioned 16 times and both have a strong relationship with the major attributes "Acknowledgement" and "Encouragement"). The confirmation that FLEs receive through encouragement and acknowledgement contribute to the enhancement of their feelings of self-efficacy by becoming more confident about their performance and self-image and boosting their self-evaluation. Both measures were identified as important facets of well-being by Forgeard et al. (2011). "Self-efficacy" is indirectly linked to "Managerial Reward" (mentioned 11 times) which, along with "Job satisfaction" (mentioned 14 times), has a strong link with one of the most important values of FLEs: "Achievement" (mentioned 16 times). Therefore, the value of "Achievement" is enhanced by the intrinsic job satisfaction feeling as well as by the extrinsic managerial reward.

Finally, one of the main drivers of FLEs to maintain a "Relationship" with the customers is the value of "Security" (mentioned 13 times) where they aim to maintain harmony and stability by staying in good terms with customers. This finding extends the concept of "dyad attachment style" - which refers to the extent to which both the customer and FLE are "able to trust and depend on other people" (Ben-Ari and Lavee, 2005, p. 622), by showing that PCF can foster their security feelings and relationship closeness.

\section{Comparison of customer and employee perspectives}

The two complex HVMs (Figures 2 and 3) showcase that a number of attributes, consequences, and values are shared between the two sets of data. However, there are several concepts that only appear in one of the HVMs but not in the other, while some repetitive concepts identified by customers and FLEs lead to different consequences and values and at varying levels of importance.

In terms of similarities, the most common attribute of PCF is "Acknowledgement". Both customers and FLEs agreed that this is the most evident and common PCF communicated during a service encounter. Moreover, "Feeling enthusiastic" is a common impact on both subgroups, displaying the strong positive emotions and feelings generated as a result of PCF communication. This extends Nasr et al.'s (2014) study advocating that PCF has a positive impact on the well-being of FLEs by operationalizing this well-being and providing concrete 
implications. More importantly, this study shows that expressing PCF can have a positive impact on the well-being of customers as well and proposes a number of well-being dimensions and implications.

Although some literature states that customers might not always aim to build relationships (Grainer et al., 2014; Jones et al., 2015), our study supports this finding but also shows that both customers and FLEs believe that relationship building enhances the feeling of security in a service encounter, and PCF is a way to achieve it. Forgeard et al. (2011) identified security as an important facet of well-being, while Gottlieb and Bergen (2010) found that social support and positive relationship building are important aspects in the overall assessments of well-being. Thus, PCF could contribute to the well-being of customers and FLEs by making them feel secure through relationship building. This finding is also important as it helps in further explaining the concept of "shared frontline experience" defined as "the tendency of a customer and FLE to undergo a similar emotional response to events that occur within their exchange relationship" (Zablah et al., 2016, p. 80). Therefore, PCF can contribute to a shared frontline experience of security fostering, relationship building and well-being enhancement.

Overall, similar to the study of Mattila and Enz (2002) which found a gap between customer and employee perceptions regarding service quality expectations, our study shows inconsistency in the perceptions of PCF between FLEs and customers.

While both customers and FLEs have generally a similar understanding of the various elements and characteristics of PCF, customers place a greater weight on "Connection" as a mean to express PCF to FLEs while FLEs favour "Encouragement". Moreover, while customers perceive "Loyalty" as an important element of PCF, FLEs do not tend to see "Loyalty" as such. This could be due to the difficulty faced by FLEs in differentiating between "Loyalty" towards the service/brand versus "Loyalty" towards themselves. Accordingly, FLEs might desire more explicit and personal forms of PCF expression while customers prefer more subtle ways to communicate PCF. Similarly, "Sensory expressiveness" seems to be more important to customers than to FLEs. This might be also due to the "Authenticity" issue that is linked to sensory expressiveness. Social psychology literature on authentic smiles and emotion recognition (Ekman and Friesen, 2003) advocates that authentic smiles stimulate more positive emotional 
reactions by respondents than do "faked" smiles. Therefore, if FLEs perceive the sensory expressiveness as unauthentic, they might not perceive it as PCF in the first place.

Surprisingly, FLEs see "Cooperation" as one of the characteristics of PCF; however, it is not the case for customers. This might be because FLEs tend to appreciate a customer who is "playing along" while the customer might not be aware that by being cooperative and engaged with the service, they are making the job of the FLE enjoyable, and, thus, the FLE perceives it as PCF. This might come as contradictory to the premise made earlier regarding FLEs needing more explicit PCF; however, in the case of "Loyalty" and "Sensory expressiveness", the FLE is a mere recipient while with "Cooperation" the FLE is equally engaged and involved in the PCF communication.

In terms of impact, this study found a number of differences between customers and FLEs. The identified list of consequences differs between customers and FLEs (Tables 4 and 5) as opposed to the identified lists of attributes and values that are shared between customers and FLEs (Tables 3 and 6). Through the HVM, it is evident that some of the consequences are shared (such as "Feeling enthusiastic", "Relationship", and "Enhanced self-image"); however, the rest of the consequences are different, and, thus, there is no room for further comparison except than by identifying what those impacts are and their weight for each subgroup (discussed in the description of Figures 2 and 3). These findings are unique to this study and extend the current customer feedback literature by uncovering various consequences of personal PCF as identified by customers and FLEs.

Finally, the most important value for customers is "Security". This finding is similar to the study of Kania and Gruber (2013), who found that customers need to feel safe and experience certainty during a service encounter. While FLEs strive the most for "Achievement" and "Benevolence", Achievement is attained by demonstrating competence according to social standards, and PCF contributes to this confirmation. Finally, the "Benevolence" value could be explained by the desire to enhance the well-being of those who staff are in direct contact with, whether family and friends (through the Spillover effect) or customers (through the feeling of responsibility FLEs have towards them). This finding is particularly important as it stresses the role and importance 
of family and friends for service employees' well-being, a topic studied in management and HR research but overlooked in service research.

\section{ZMET-Towards a deeper understanding}

As previously mentioned, ZMET was used to help gain a deeper understanding of the constructs elicited through traditional laddering probes. Therefore, after reviewing all the collected images and transcripts; similarities, differences and/or relationships between the concepts that can help understand PCF phenomenon in greater depth and beyond the HVMs, were thoroughly searched (Giorgi, 1989). Accordingly, empirically grounded key themes were identified: mutual mistrust, counterintuitive impact of PCF, and the role of management. These themes complement our understanding of the knowledge gained through laddering.

\section{Mutual mistrust}

Through our interviews, we identified a mutual mistrust between service customers on one side and service employees/organizations on the other. We found evidence that customers believe that organizations strive to abuse them, while employees' believe that customers are, in their majority, opportunistic and selfish. Nevertheless, employees are being trained to understand and deal with customers for the benefit of the service. However, the generic feeling that customers have towards FLEs and service organizations, in most of the cases, is associated with negative and abusive connotations. This finding provides empirical evidence to the conceptual work of Fisk (2009) stating that current service practices are "designed to control customers than to serve customers" (p. 17). For example, our findings show that customers perceive FLEs as being driven by power and achievement. Similarly, FLEs believe that customers are opportunistic and seek personal benefits when expressing PCF.

\section{Counterintuitive impacts of PCF}

Although the study focuses on a positive topic (PCF), respondents interestingly also mentioned negative consequences of PCF. Respondents were not specifically probed for these but they still mentioned them. These were issues such as "complacent behaviour", "embarrassment", "feeling discomfort", "increased workload", “internal confrontation," and "pressure from raised expectations". These findings support Nasr et al.'s (2015) study stating that PCF can have 
negatives consequences too. Moreover, our study shows that customers believe that PCF might not always have an impact on FLEs, and this, according to our findings, seems to be a reason for some customers to be reluctant in giving PCF since they mentioned that employees "might not care" about the PCF received, or "have limited time to respond" or simply "see it as part of their job". In contrast, FLEs discussed being frustrated when customers do not give them PCF, especially when they feel that they went the "extra mile" for the customer. Finally, this study adds to Nasr et al.'s (2015) work, which explored the negative consequences of PCF on the wellbeing of FLEs, by revealing that PCF can sometimes have a negative impact on the customer as well, for example, in the form of pressure and experienced discomfort. This is especially evident when the customer feels "tricked" or forced into giving PCF, for example, when the FLE explicitly pushes the customer to give positive feedback or when there is a valuable incentive linked to feedback, or when feedback is expected in the presence of others. This comes in accordance with the emotional labour literature. Emotional labour is defined as "the expression of organizationally desired emotions during interpersonal transactions" (Morris and Feldman, 1996, p. 987). The service literature is rich with empirical studies on emotional labour in servicerelated occupations with a predominant focus on the negative impact of emotional labour on FLEs. However, Bailey et al. (2001) propose that customers also engage in forms of emotional labour. This is particularly evident when the customer invests an emotional effort during a service interaction. Finally, our results show that the various characteristics, elements, and impacts of PCF are not mutually exclusive and could be expressed and experienced during the same service encounter.

\section{The role of management}

Our findings support Kaoa et al.'s (2015) premise, claiming that although FLEs have the potential and power to nurture customer and organizational well-being, their ability depends on the presence of transformational management in the company. Many FLEs mentioned the role of management and the current internal feedback systems as prerequisites for proper feedback understanding and handling by FLEs. Respondents discussed at length the importance of positive feedback management with regard to how positive feedback is captured, recorded, recognized, and acted upon within the organization. Employees confirmed that the internal feedback management system and the way customer feedback is handled internally is what affects the 
impact of PCF on the employee. This comes in accordance with Nasr et al.'s (2015) study, where "management of positive feedback" was identified as a key contingency of PCF impact. In addition, employees mentioned experiencing frustration when the positive feedback received is not appreciated internally. This finding can be explained by the expectancy theory (Vroom, 1964), where individuals' levels of morale are negatively affected when they feel that their efforts are not being appreciated.

\section{Managerial Implications}

Our findings suggest a number of important managerial implications. First, regarding the solicitation of customer feedback, companies should encourage customers to express PCF. In a recent study, Bone et al. (2017) found that starting a customer survey with open-ended questions soliciting positive feedback (e.g. by asking what went well) increased customer purchase behaviour as the focus on their positive experiences indirectly affects their future behaviour. Similarly, our findings show additional benefits of communicating and receiving personal PCF, therefore, we encourage FLEs to ask customers directly to express what went well in a service encounter. Moreover, by inviting customers to speak about their positive experiences, managers can learn new and unexpected details. Similarly, they can ask specific follow-up questions which can help identify the important element of the service as well as what makes the service stand out from competitors. Unfortunately, many companies miss out on this relatively easy but equally important lever in customer acquisition strategy. Companies can compile the received PCF and communicate it back to the public in the form of quotes and narratives from satisfied customers used on the company website and social media sites. This authentic type of communication could attract more customers than other more expensive and time consuming customer acquisition campaigns.

Our results also show that communicating PCF has an uplifting impact on the person giving the feedback. Therefore, in addition to encouraging customers to share the PCF in person, we encourage companies to solicit positive feedback on social media and review sites such as Facebook and TripAdvisor. This will not only be beneficial to the company and its future customers but also to the person expressing this feedback. This is particularly important since 
research shows that customers experiencing good moods tend to see the positive side of things and are more willing to return to the store (Tsai and Huang, 2002).

In addition, given that service experiences require customer participation (Verhoef et al., 2009), soliciting positive customer feedback would allow customers to positively enhance their experiences. This could be achieved by creating innovative incentives making the process of feedback-giving fun and entertaining by for example using gamification, which is an "informal umbrella term for the use of game elements in non-gaming systems to improve user experience and user engagement" (Deterding et al., 2011, p. 9). Companies could also work on designing processes capable of generating high levels of gratitude, allowing customers to reciprocate and prevent them from guilt rationalization (Palmatier et al., 2009).

Second, regarding the management of FLEs, managers should be aware of the vital impact PCF has on FLEs. Our results show that FLEs' enthusiasm is linked to a number of positive outcomes such as higher job motivation, job satisfaction, and a strong spillover effect. In addition, PCF contributes to a positive self-evaluation which can counterbalance the feelings of depression that many FLEs face at work (Worth, 2010). This is particularly important as upward spirals of positive emotions counter downward spirals of negativity (Garland et al., 2010). Moreover, PCF for FLEs is associated with their level of achievement; thus, it could be used as a tool by management to evaluate FLEs' performances. Nevertheless, caution should be exercised concerning the weight or impact PCF has on FLEs, as Nasr et al. (2015) found that PCF can have "negative" or "no impact" on FLEs. Furthermore, just as FLEs are being trained to identify and respond to the different types of customer complaints (Davidow, 2003), they could also be trained to identify, understand, and respond to all types of PCF. This supports Delcourt et al.'s (2016) findings, inviting managers to strengthen the Employee Emotional Competence (EEC) on all levels. Emotional competence implies the manifestation of emotionally competent behaviours (Seal and Andrews-Brown, 2010) that exhibit emotional intelligence (EI). Research shows that EEC can be learned and improved with training and is known to affect FLEs' well-being (Kotsou et al., 2011). With regards to FLEs' training techniques, a perspective-taking technique could be adopted, which puts employees in the customers' shoes (e.g., role playing, videotaping, mystery shopping) and thereby increases their ability to adopt a customer's viewpoint (Parker and Axtell, 2001). Moreover, it would be useful to develop a portfolio of diagnostic cues of various PCF 
elements and characteristics to help employees identify the various cues and respond accordingly. In this regards, FLEs should be capable to ascertain the customer's perspective of the service encounter and to sense and share the customer emotions generated during the interaction.

Third, there should be a careful examination of positive service encounters as they are crucial for the development and sustainment of customer-employee relationships. Service encounters designed to improve customer service experience should focus on delivering customer comfort, reinforcing their feeling of control and safety, and building a relationship with the FLE. Interestingly, our findings suggest that FLEs value human connection and relationships with customers as it gives them a feeling of security and enhances their benevolence value. However, the challenge lies in making the customer perceive the employee as genuinely engaged and concerned. Accordingly, managers should make the process of building and maintaining genuine relationships between customers and FLEs comfortable and transparent. Accordingly, “interaction routing" (van Dolen et al., 2002) could be adopted, where employees and customers are matched based on personalities and preferred manners of interactions. This could be achieved by profiling customers and employees in advance of service encounters. With the advancement in technology and text analysis allowing organizations to analyse language patterns, customer and employee profiling could be fostered.

\section{Limitations and Directions for Further Research}

This study has a number of limitations that suggests potential avenues for further research. Due to the explorative nature of the study and the size of the sample, the findings are tentative. Further empirical studies should use probability samples that represent a broader population of customers and FLEs and conduct studies to test and measure the strength of the identified relationships.

Secondly, as we conducted personal interviews, there is always the possibility of interviewer bias; however, the interviewer, who is trained and experienced in this method, made all attempts to remain neutral and avoid asking leading questions or illicit hoped-for answers. 
Thirdly, although we position PCF as a dyadic construct, our participants did not describe the same incident of PCF (similarly to the approach adopted by Gremler and Gwinner, 2008). Future studies could investigate both parties in the dyad of a single incident to obtain a singular picture of PCF perceptions. Another option would be to use a triadic approach, by including the management perspective, as we found that managers play an important role in influencing the impact of PCF on FLEs. This approach could be implemented through the usage of case studies. This would help researchers to better understand the nature of PCF communication and the managerial viewpoint regarding PCF management. Future research could also look at the impact of positive feedback given by a FLE to a customer. It would be of interest to explore the impacts of this feedback on both the customer and the FLE.

Another avenue for future research could be to investigate the cross-cultural stability of our findings. Future research should consider the extent to which cultural differences affect the display, consequences, and importance associated with PCF. Moreover, we did not consider the personal characteristics of FLEs and customers, such as demographic information and personality traits, future research could consider the effect of these variables. Finally, we acknowledge that service encounters vary between and within different contexts and industries and therefore we invite future research to focus on various service contexts such as healthcare, education, transport, and social media. Similarly, as retail, hospitality, and tourism sectors were mainly examined through the data collection, we encourage focusing on further industries such as banking, and utilities. Accordingly, by focusing on particular service industries, a more complete understanding of PCF within each industry will be achieved. Thus, there is a need to expand this study geographically, culturally and industry wise. Thus, future research could study the extent to which these differences affect the display, motivation, contingencies, impacts, and values associated with PCF.

This paper also hopes to stimulate a methodological discussion and invite future researchers to utilize the integrated laddering and ZMET methodology as an appropriate exploratory instrument. From a method point of view, the usage of images proved to be particularly beneficial in engaging the participants to begin talking about their perceptions, be they conscious or unconscious, of PCF. Lastly, as PCF is still scarcely studied within service research, more exploratory studies are needed to further investigate positive service experiences. 


\section{Conclusion}

The purpose of this study was to highlight the importance and extend the understanding of the underresearched concept of personal PCF. Through a novel integrated methodological approach and by comparing and contrasting customers' and FLEs' perspectives, we revealed the main elements, characteristics of personal PCF, its various impacts, and the perceived importance of this phenomenon for both parties. Through our rich findings, we conceptualized PCF in the service literature and positioned it as an important concept within customer feedback literature. We also extended PCF understanding beyond what the current literature shows (i.e. gratitude, compliments) by identifying nine characteristics of personal PCF. Subsequently, we revealed a number of potential impacts on both customers and FLEs. Interestingly, we found that both customers and FLEs have a similar understanding of the various elements and characteristics of personal PCF, however, the significance of the various elements and the subsequent impacts vary between the two groups. Finally, we discussed three key themes in PCF handling that help position PCF within the extant customer management literature. This study contributes to a wellrounded understanding of customer feedback by counter-balancing the prevailing focus on customer complaining behaviour and proposing a complimentary look at the positive valence of personal feedback. It also provides managerial implications concerning the management of positive service encounters, an emerging topic within service research.

\section{References}

Altinay, L., Saunders, M.N. and Wang, C.L. (2014), "The influence of culture on trust judgments in customer relationship development by ethnic minority small businesses", Journal of Small Business Management, Vol. 52 No. 1, pp. 59-78.

Bailey, J.J., Gremler, D.D. and McCollough, M.A. (2001), "Service encounter emotional value", Services Marketing Quarterly, Vol. 23 No. 1, pp. 1-24.

Barnett, W., Foos, A., Gruber, T., Keeling, D., Keeling, K. and Nasr, L. (2014), "Consumer perceptions of interactive service robots : a value - dominant logic perspective", The 23rd IEEE International Symposium on Robot and Human Interactive Communication, Edinburgh, UK, pp. 1134-1139. 
Baron, S. and Warnaby, G. (2011), "Individual customers' use and integration of resources: empirical findings and organisational implications in the context of value co creation", Industrial Marketing Management, Vol. 40 No. 2, pp. 211-218.

Baron, S., Warnaby, G. and Hunter-Jones, P. (2014), "Service(s) marketing research: developments and directions", International Journal of Management Reviews, Vol. 16 No. 2, pp. 150-171.

Bartlett, M.Y. and DeSteno, D. (2006), "Gratitude and prosocial behavior: helping when it costs you", Psychological Science, Vol. 17 No. 4, pp. 319-325.

Ben-Ari, A. and Lavee, Y. (2005), "Dyadic characteristics of individual attributes: attachment, neuroticism, and their relation to marital quality and closeness", American Journal of Orthopsychiatry, Vol. 75 No. 4, pp. 621-631.

Berry, L.L. (1995), "Relationship marketing of services-growing interest, emerging perspectives", Journal of the Academy of Marketing Science, Vol. 23 No. 4, pp. 236-245.

Berry, L.L. and Parasuraman, A. (1997), "Listening to the customer-the concept of a servicequality information system", Sloan Management Review, Vol. 38 No. 3, pp. 65-76.

Best, A. and Andreasen, A.R. (1977), "Consumer response to unsatisfactory purchases: a survey of perceiving defects, voicing complaints, and obtaining redress", Law \& Society Review, Vol. 11 No. 4, pp. 701-742.

Bitner, M. J., Booms, B.H. and Tetreault, M.S. (1990), "The service encounter: diagnosing favorable and unfavorable incidents", Journal of Marketing, Vol. 54 No. 1, pp. 71-84.

Bitran, G.R. and Hoech, J. (1990), "The humanization of service: respect at the moment of truth", Sloan Management Review, Vol. 31 No. 1, pp. 89-96.

Bone, S.A., Lemon, K.N., Voorhees, C.M., Liljenquist, K.A., Fombelle, P.W., Detienne, K.B. and Money, R.B. (2017), "Mere measurement plus": How solicitation of open-ended positive feedback influences customer purchase behavior", Journal of Marketing Research, Vol. 54 No. 1, pp.156-170.

Brodie, R.J., Hollebeek, L.D., Juric, B. and Ilic, A. (2011), "Customer engagement: conceptual domain, fundamental propositions, and implications for research", Journal of Service Research, Vol. 14 No. 3, pp. 252-272.

Caemmerer, B. and Wilson, A. (2010), "Customer feedback mechanisms and organisational learning in service operations", International Journal of Operations and Production Management, Vol. 30 No. 3, pp. 288-311.

Christensen, G.L. and Olson, J.C. (2002), "Mapping consumers' mental models with ZMET", Psychology and Marketing, Vol. 19 No. 6, pp. 477-501. 
Claeys, C., Swinnen, A. and van den Abeele, P. (1995), “Consumers' means-end chains for think and feel products", International Journal of Research in Marketing, Vol. 12 No. 3, pp. 193208.

Corbin, J. and Strauss, A. L. (2008), The Basics of Qualitative Research, 3rd ed., Sage, Thousand Oaks, CA.

Coulter, R.H. and Zaltman, G. (1994), "Using the Zaltman Metaphor Elicitation Technique to understand brand images", in Allen, C.T. and John, D.R. (Eds.),Advances in Consumer Research Volume 21, Association for Consumer Research, Provo, UT, pp. 501-507.

Daunt, K.L. and Harris, L. (2014), "Linking employee and customer misbehaviour: the moderating role of past misdemeanours", Journal of Marketing Management, Vol. 30 No. $3-4$, pp. 221-244.

Davidow, M. (2003), "Organizational responses to customer complaints: what works and what doesn't”, Journal of Service Research, Vol. 5 No. 3, pp. 225-250.

Day, R.L. and Landon, E.L. (1977), Toward a Theory of Consumer Complaint Behaviour, Consumer and Industrial Buying Behavior, North Holland, New York, NY.

Deeter-Schmelz, D.R., Goebel, D.J. and Kennedy, K.N. (2002), "Understanding sales manager effectiveness: the link between the sales force and a dynamic marketplace", Industrial Marketing Management, Vol. 31 No. 7, pp. 617-626.

Delcourt, C., Gremler, D., De Zanet, F. and van Riel, A. (2017), "An Analysis of the interaction effect between employee technical and emotional competencies in emotionally charged service encounters", Journal of Service Management, Vol. 28 No. 1, pp. 85-10.

Delcourt, C., Gremler, D.D., van Riel, A. and van. Birgelen, M. (2016), "Employee emotional competence: construct conceptualization and validation of a customer-based measure", Journal of Service Research, Vol 19 No 1, pp. 72- 87.

Deterding, S., Dixon, D., Khaled, R. and Nacke, L. (2011), "From game design elements to gamefulness: defining gamification", Proceedings of the 15th International Academic MindTrek Conference: Envisioning Future Media Environments, pp. 9-15.

Eisenberger, R., Fasolo, P. and Davis-LaMastro, V. (1990), "Perceived organizational support and employee diligence, commitment, and innovation", Journal of Applied Psychology, Vol. 75 No. 1, pp. 51-59.

Ekman, P. and Friesen, W. V. (2003), Unmasking the Face: A Guide to Recognizing Emotions from Facial Clues, Malor Books, Los Altos, CA. 
Emmons, R.A. and McCullough, M.E. (2003), "Counting blessings versus burdens: an experimental investigation of gratitude and subjective well-being in daily life", Journal of Personality and Social Psychology, Vol. 84 No. 2, pp. 377-389.

Erickson, S.G. and Ecktich, D.W. (2001), "Consumer affairs responses to unsolicited customer compliments", Journal of Marketing Management, Vol. 17 No. 3-4, pp. 321-340.

Fisk, R. (2009), “A customer liberation manifesto”, Service Science, Vol. 1 No. 3, pp. 135-141.

Forgeard, M.J.C., Jayawickreme, E., Kern, M.L. and Seligman, M.E.P. (2011), "Doing the right thing: measuring well-being for public policy", International Journal of Wellbeing, Vol. 1 No. 1, pp. 79-106.

Forman, J. and Damschroder, L. (2008), "Qualitative content analysis", Empirical Research for Bioethics: A Primer, Elsevier Publishing, Oxford, UK, pp. 39-62.

Frow, P. and Payne, A. (2009), "Customer relationship management: a strategic perspective", Journal of Business Market Management, Vol. 3 No. 1, pp. 7-27.

Fundin, A.P. and Bergman, B.L.S. (2003), "Exploring the customer feedback process", Measuring Business Excellence, Vol. 7 No. 2, pp. 55-65.

Gable, S.L. and Haidt, J. (2005), "What (and why) is positive psychology?", Review of General Psychology, Vol. 9 No. 2, pp. 103-110.

Garland, E.L., Fredrickson, B., Kring, A.M., Johnson, D.P., Meyer, P.S. and Penn, D.L. (2010), "Upward spirals of positive emotions counter downward spirals of negativity: insights from the broaden-and-build theory and affective neuroscience on the treatment of emotion dysfunctions and deficits in psychopathology", Clinical Psychology Review, Vol. 30 No. 7,

Gengler, C.E., Klenosky, D.B. and Mulvey, M.S. (1995), "Improving the graphic representation of means-end results", International Journal of Research in Marketing, Vol. 12 No. 3, pp. $245-256$.

Gengler, C.E. and Reynolds, T.J. (1993), "LADDERMAP: a software tool for analyzing laddering data, version 5.4."

Gentile, C., Spiller, N. and Noci, G. (2007), "How to sustain the customer experience: an overview of experience components that co-create value with the customer", European Management Journal, Vol. 25 No. 5, pp. 395-410.

Giorgi, A.P. (1989), "Learning and memory from the perspective of phenomenological psychology", in Valle, R.S. and Halling, S. (Eds.),Existential-Phenomenological Perspectives in Psychology, Plenum, New York, NY, pp. 99-112. 
Gottlieb, B.H. and Bergen, A.E. (2010), "Social support concepts and measures", Journal of Psychosomatic Research, Vol. 69 No. 5, pp. 511-520.

Grainer, M., Noble, C.H., Bitner, M.J. and Broetzmann, S.M. (2014), "What unhappy customers want”, MIT Sloan Management Review, Vol. 55 No. 3, pp. 31-35.

Grant, A. and Gino, F. (2010), "A little thanks goes a long way: explaining why gratitude expressions motivate prosocial behavior", Journal of Personality and Social Psychology, Vol. 98 No. 6, pp. 946-955.

Gremler, D.D., and Gwinner, K.P., "Rapport-building behaviors used by retail employees", Journal of Retailing, Vol. 84 No. 3, pp. 308-324.

Groth, M., Hennig-Thurau, T. and Walsh, G. (2009), "Customer reactions to emotional labor: the roles of employee acting strategies and customer detection accuracy", Academy of Management Journal, Vol. 52 No. 5, pp. 958-974.

Gruber, T., Reppel, A.E., Szmigin, I. and Voss, R. (2008), "Revealing the expectations and preferences of complaining customers by combining the laddering interviewing technique with the Kano model of customer satisfaction", Qualitative Market Research: An International Journal, Vol. 11 No. 4, pp. 400-413.

Grunert, K.G. and Grunert, S.C. (1995), "Measuring subjective meaning structures by the laddering method: theoretical considerations and methodological problems", International Journal of Research in Marketing, Vol. 12 No. 3, pp. 209-225.

Gutman, J. (1982), “A means-end chain model based on consumer categorization processes", Journal of Marketing, Vol. 46 No. 2, pp. 60-72.

Henneberg, S.C., Gruber, T., Reppel, A., Naudé, P., Ashnai, B., Huber, F. and Chowdhury, I.N. (2015), "A cross-cultural comparison of business complaint management expectations", Journal of Marketing Theory and Practice, Vol. 23 No. 3, pp. 254-271.

Hennig-Thurau, T., Groth, M., Paul, M. and Gremler, D.D. (2006), "Are all smiles created equal? how emotional contagion and emotional labor affect service relationships", Journal of Marketing, Vol. 70 No. 3, pp. 58-73.

Hennink, M.H., Hutter, I. and Bailey. A. (2011), Qualitative Research Methods, SAGE Publications Ltd., London.

Heskett, J., Jones, T., Loveman, G., Sasser, W. and Schlesinger, A. (1994), "Putting the service profit chain to work", Harvard Business Review, Vol. 72 No. 2, pp. 164-174.

Howells, K. and Cumming, J. (2012), "Exploring the role of gratitude in the professional experience of pre-service teachers", Teaching Education, Vol. 23 No. 1, pp. 71-88. 
Iacobucci, D., Grayson, K., and Rust, R. (2001), "Interrater reliability", Journal of Consumer Psychology, Vol. 10 No.1-2, pp. 71-73.

Jones, M.A., Reynolds, K.E., Arnold, M.J., Gabler, C.B., Gillison, S.T. and Landers, V.M., (2015), "Exploring consumers' attitude towards relationship marketing", Journal of Services Marketing, Vol. 29 No. 3, pp.188-199.

Kania, N. and Gruber, T. (2013), "Understanding satisfying service encounters in retail banking - a dyadic perspective", International Journal of Services, Economics and Management, Vol. 5 No. 3, pp. 222-255.

Keegan, S. (2009), Qualitative Research: Good Decision Making Through Understansing People, Cultures and Markets, Kogan Page Publishers.

Kaoa, P.-J., Paib, P., Lina, T. and Zhonga, J.-Y. (2015), "How transformational leadership fuels employees' service innovation behavior", The Service Industries Journal, Vol. 35 No. 7-8, pp. $448-466$.

Kotsou, I., Gregoire, J., Nelis, D. and Mikolajczak, M. (2011), "Emotional plasticity: conditions and effects of improving emotional competence in adulthood", Journal of Applied Psychology, Vol. 96 No. 4, pp. 827-839.

Kraft, F. and Martin, C. (2001), "Customer compliments as more than complementary feedback", Journal of Consumer Satisfaction, Dissatisfaction and Complaining Behavior, Vol. 14, pp. 1-13.

Krippendorff, K. (2004), Content Analysis, Sage, Thousand Oaks, CA.

Kunz, W.H. and Hogreve, J. (2011), "Toward a deeper understanding of service marketing: the past, the present, and the future", International Journal of Research in Marketing, Vol. 28 No. 3, pp. 231-247.

Larivière, B., Bowen, D., Andreassen, T. W., Kunz, W., Sirianni, N. J., Voss, C., Wünderlich, N. V. and De Keyser, A. (2017), "'Service Encounter 2.0": an investigation into the roles of technology, employees and customers", Journal of Business Research.

Lee, M.S.Y., McGoldrick, P.J., Keeling, K.A. and Doherty, J. (2003), "Using ZMET to explore barriers to the adoption of $3 \mathrm{G}$ mobile banking services", International Journal of Retail \& Distribution Management, Vol. 31 No. 6, pp. 340-348.

Litvin, S.W., Goldsmith, R.E. and Pan, B. (2008), "Electronic word-of-mouth in hospitality and tourism management", Tourism Management, Vol. 29 No. 3, pp. 458-468.

Lusch, R.F., Vargo, S.L. and O’Brien, M. (2007), "Competing through service: insights from service-dominant logic", Journal of Retailing, Vol. 83 No. 1, pp. 5-18. 
Malhotra, N. and Birks, D. (2006), Marketing Research: An Applied Approach, 2nd European ed., Pearson Education, Harlow.

Martinuzzi, B. (2009), The Leader As A Mensch: Become The Kind Of Person Others Want To

Mattila, A.S. and Enz, C.A. (2002), "The role of emotions in service encounters", Journal of Service Research, Vol. 4 No. 4, pp. 268-277.

Mattila, A.S. and Wirtz, J. (2004), "Complaining to firms: the determinants of channel choice", Journal of Services Marketing, Vol. 18 No. 2, pp. 147-155.

Morris, J.A. and Feldman, D.C. (1996), "The dimensions, antecedents, and consequences of emotional labor", Academy of Management Review, Vol. 21 No. 4, pp. 986-1010.

Nasr, L., Burton, J. and Gruber, T. (2015), "When good news is bad news: the negative impact of positive customer feedback on front-line employee well-being", Journal of Services Marketing, Vol. 29 No. 6/7, pp. 599-612.

Nasr, L., Burton, J., Gruber, T. and Kitshoff, J. (2014), "Exploring the impact of customer feedback on the well-being of service entities: a TSR perspective", Journal of Service Management, Vol. 25 No. 4, pp. 531-555.

Olson, J.C. and Reynolds, T.J. (2001), "The means-end approach to understanding consumer decision making", in Olson, J.C. and Reynolds, T.J. (Eds.),Understanding Consumer Decision Making: The Means-end Approach to Marketing and Advertising Strategy, Lawrence Erlbaum, Mahwah, NJ., pp. 3-20.

Ordenes, F. V., Theodoulidis, B., Burton, J., Gruber, T. and Zaki, M. (2014), "Analyzing customer experience feedback using text mining: a linguistics-based approach", Journal of Service Research, Vol. 17 No. 3, pp. 278-295.

Palmatier, R.W., Jarvis, C.B., Bechkoff, J.R. and Kardes, F.R. (2009), "The role of customer gratitude in relationship marketing”, Journal of Marketing, Vol. 73 No. 5, pp. 1-18.

Palmer, A. (2010), "Customer experience management: a critical review of an emerging idea", Journal of Services Marketing, Vol. 24 No. 3, pp. 196-208.

Parker, S.K. and Axtell, C.M. (2001), "Seeing another viewpoint: antecedents and outcomes of employee perspective taking", Academy of Management Journal, Vol. 44 No. 6, pp. 10851110.

Patterson, P.G., M.K. Brady, and McColl-Kennedy, J.R. (2016), "Geysers or bubbling hot springs? a cross-cultural examination of customer rage from eastern and western perspectives", Journal of Service Research, Vol. 19 No. 3, pp. 243-259. 
Poblete, B. and Baeza-Yates, R. (2008), “Query-sets: using implicit feedback and query patterns to organize web documents", Proceeding of the 17th international conference on World Wide Web - WWW '08, ACM Press, New York, NY, pp. 41-50.

Perreault, W. D., and Leigh, L. E. (1989), "Reliability of nominal data based on qualitative judgments", Journal of Marketing Research, Vol. 26 No. 2, p. 135.

Pugh, S. D. (2001), "Service with a smile: Emotional contagion in the service encounter", Academy of Management Journal, Vol. 44 No.5, pp. 1018-1027.

Reynolds, T.., Dethloff, C. and Westberg, S.J. (2001), "Advances in laddering”, in Reynolds, T.J. and Olson, J.C. (Eds.),Understanding Consumer Decision Making - The Means-End Approach to Marketing and Advertising Strategy, Lawrence Erlbaum Associates, Mahwah, NJ., pp. 91-111.

Reynolds, T.J. and Gutman, J. (1988), "Laddering theory, method, analysis, and interpretation", Journal of Advertising Research, Vol. 28 No. 1, pp. 11-31.

Reynolds, T.J. and Phillips, J.M. (2008), "A review and comparative analysis of laddering research methods: recommendations for quality metrics", Review of Marketing Research, Vol. 5, pp. 130-174.

Rodríguez-Muñoz, A., Sanz-Vergel, A.I., Demerouti, E. and Bakker, A.B. (2014), "Engaged at work and happy at home: A spillover-crossover model", Journal of Happiness Studies, Vol. 15 No. 2, pp.271-283.

Robinson, L.M. and Berl, R.L. (1979), "What about compliments? a follow-up study on customer complaints and compliments", Refining Concepts and Measures of Consumer Satisfaction and Complaining Behavior, Papers from the fourth annual conference on Consumer Satisfaction, Dissatisfaction and Complaining Behavior, Bloomington, Indiana, pp. 144-148.

Roger, C. and Farson, R.E. (1984), "Active listening”, in Kold, D.A. and McIngyre, J. (Eds.),Organizational Psychology, Prentice Hall, New York, NY, pp. 255-266.

Rokeach, M. (1973), Understanding Human Values, The Free Press, New York, NY.

Sampson, S.E. (1996), "Ramifications of monitoring service quality through passively solicited customer feedback", Decision Sciences, Vol. 27 No. 4, pp. 601-622.

Schwartz, S.H. (1994), "Are there universal aspects in the structure and content of human values?", Journal of Social Issues, Vol. 50 No. 4, pp. 19-45.

Seal, C.R. and Andrews-Brown, A. (2010), "An integrative model of emotional intelligence: emotional ability as a moderator of the mediated relationship of emotional quotient and emotional competence", Organization Management Journal, Vol. 7 No. 2, pp. 143-152. 
Tsai, W.-C. and Huang, Y.-M. (2002), "Mechanisms linking employee affective delivery and customer behavioral intentions", Journal of Applied Psychology, Vol. 87 No. 5, pp. 10011008.

Van Doorn, J., Lemon, K.N., Mittal, V., Nass, S., Pick, D., Pirner, P. and Verhoef, P.C. (2010), "Customer engagement behavior: theoretical foundations and research directions", Journal of Service Research, Vol. 13 No. 3, pp. 253-266.

Van Dolen, W., Lemmink, J., De Ruyter, K. and De Jong, A. (2002), "Customer-sales employee encounters: a dyadic perspective", Journal of Retailing, Vol. 78 No. 4, pp.265-279.

Verhoef, P.C. (2003), "Understanding the effect of customer relationship management efforts on customer retention and customer share development", Journal of Marketing, Vol. 67 No. 4, pp. $30-45$.

Verhoef, P.C., Lemon, K.N., Parasuraman, A., Roggeveen, A., Tsiros, M. and Schlesinger, L. A. (2009), "Customer experience creation: determinants, dynamics and management strategies”, Journal of Retailing, Vol. 85 No. 1, pp. 31-41.

Verhoef, P.C., Reinartz, W.J. and Krafft, M. (2010), "Customer engagement as a new perspective in customer management”, Journal of Service Research, Vol. 13 No. 3, pp. $247-252$.

Voss, C.A., Roth, A. V., Rosenzweig, E.D., Blackmon, K. and Chase, R.B. (2004), "A tale of two countries' conservatism, service quality, and feedback on customer satisfaction", Journal of Service Research, Vol. 6 No. 3, pp. 212-230.

Vroom, V.H. (1964), Work and Motivation, Wiley, New York.

Weißhaar, I. and Huber, F. (2016), "Empathic relationships in professional services and the moderating role of relationship age", Psychology \& Marketing, Vol. 33 No. 7, pp.525-541.

Wieseke, J., Geigenmuller, A. and Kraus, F. (2012), "On the role of empathy in customeremployee interactions”, Journal of Service Research, Vol. 15 No. 3, pp. 316-331.

Wirtz, J., Tambyah, S.K. and Mattila, A.S. (2010), “Organizational learning from customer feedback received by service employees: a social capital perspective", Journal of Service Management, Vol. 21 No. 3, pp. 363-387.

Wirtz, J. and Tomlin, M. (2000), "Institutionalizing customer-driven learning through fully integrated customer feedback systems", Managing Service Quality, Vol. 10 No. 4, pp. 205215.

Witell, L., Kristensson, P., Gustafsson, A. and Löfgren, M. (2011), "Idea generation: customer co-creation versus traditional market research techniques", Journal of Service Management, Vol. 22 No. 2, pp. 140-159. 
Worth, T. (2010), “Ten careers with high rates of depression", available at: http://www.health.com/health/gallery/0,,20428990,00.html (accessed 1 August 2015).

Young, M.E. and Hutchinson, T.S. (2012), "The rediscovery of gratitude: implications for counseling practice", Journal of Humanistic Counceling, Vol. 51 No. 1, pp. 99-113.

Zablah, A.R., Sirianni, N.J., Korschun, D., Gremler, D.D. and Beatty, S.E. (2016), "Emotional convergence in service relationships: the shared frontline experience of customers and employees", Journal of Service Research, Vol. 20 No. 1, pp. 76-90.

Zaltman, G. (1997), "Rethinking market research: putting people back in", Journal of Marketing Research, Vol. 34 No. 4, pp. 424-437.

Zaltman, G. and Higie, R.A. (1993), Seeing The Voice of The Customer: The Zaltman Metaphor Elicitation Technique, Marketing Science Institute, Cambridge, MA.

Zeithaml, V.A., Berry, L.L. and Parasuraman, A. (1996), "The behavioral consequences of service quality", Journal of Marketing, Vol. 60 No. 2, pp.31-46. 
Table 1: Characteristics of customer and FLE samples

\begin{tabular}{lcc}
\hline & Customers & FLEs \\
\hline $\begin{array}{l}\text { Number of participants } \\
\text { Gender }\end{array}$ & 20 & 20 \\
$\quad$ Male & $35 \%$ & $35 \%$ \\
Female & $65 \%$ & $65 \%$ \\
Age & & \\
$\quad$ Average & 29 & 36 \\
$\quad$ Minimum & 21 & 24 \\
$\quad$ Maximum & 55 & 63 \\
Years of employment & & \\
$\quad$ Average & --- & 15 \\
$\quad$ Minimum & --- & 4 \\
$\quad$ Maximum & --- & 51 \\
\hline
\end{tabular}




\section{Table 2: Laddering variations}

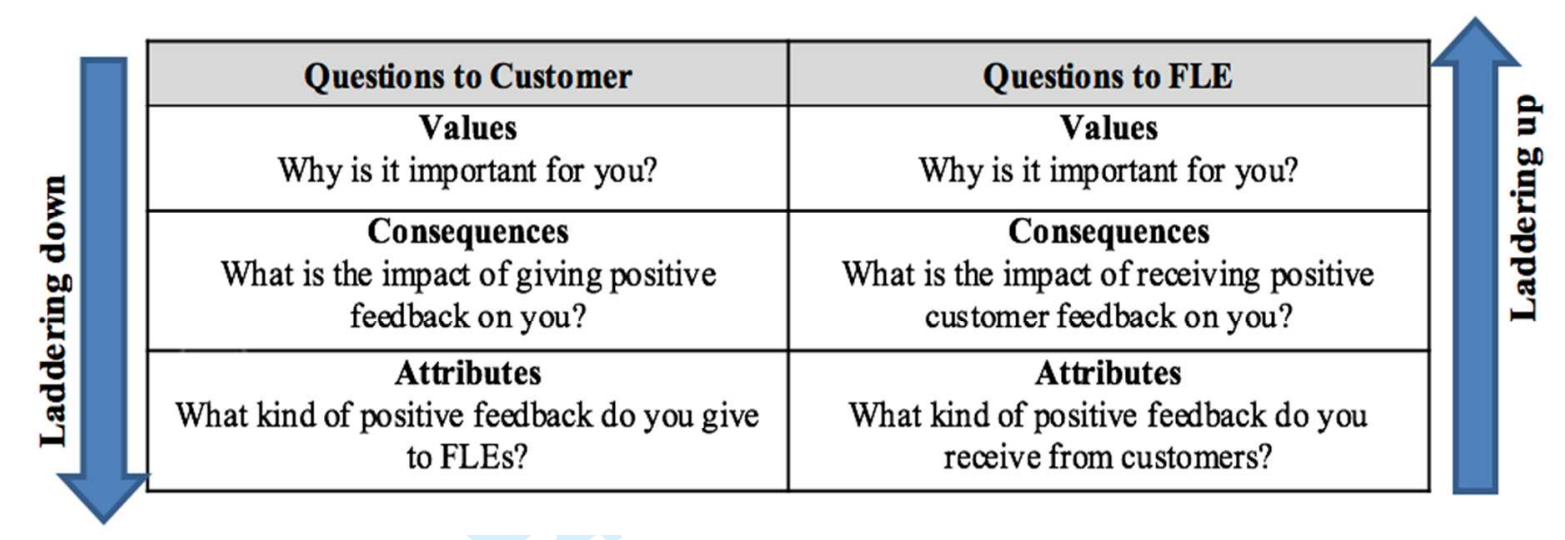


Table 3: Overview of PCF attributes

\begin{tabular}{|c|c|c|c|}
\hline Name of attribute & $\begin{array}{l}\text { Number of times } \\
\text { mentioned by } \\
\text { customers } \\
\text { (in ladders) }\end{array}$ & $\begin{array}{l}\text { Number of } \\
\text { times } \\
\text { mentioned } \\
\text { by FLEs } \\
\text { (in ladders) }\end{array}$ & Description \\
\hline Acknowledgment & 84 & 147 & $\begin{array}{l}\text { Customer acknowledges and recognises that something positive } \\
\text { occurred. } \\
\text { e.g. "This is very good" }\end{array}$ \\
\hline Connection & 75 & 43 & $\begin{array}{l}\text { Customer creates a personal bond by exchanging feelings of care and } \\
\text { friendliness which might help build personal connections leading to } \\
\text { the development of relationships with the employee. } \\
\text { e.g. "Remembering the name of the FLE, engaging in humour" }\end{array}$ \\
\hline Cooperation & 18 & 28 & $\begin{array}{l}\text { Customer is fully cooperating and engaged with the service. } \\
\text { e.g. "Trying new food, wanting to learn more" }\end{array}$ \\
\hline Counsel & 11 & 7 & $\begin{array}{l}\text { Customer gives suggestions and constructive critical reviews. } \\
\text { e.g. "Giving tips on how to make the service even better" }\end{array}$ \\
\hline Encouragement & 92 & 96 & $\begin{array}{l}\text { Customer shows support and social encouragement. } \\
\text { e.g. "Recommending the FLE for a reward, or talking about him to } \\
\text { the manager". }\end{array}$ \\
\hline Gifts and tips & 14 & 6 & $\begin{array}{l}\text { Customer offers a tangible gift or monetary tips as an expression of } \\
\text { PCF. }\end{array}$ \\
\hline Gratitude & 26 & 30 & $\begin{array}{l}\text { Customer expresses his gratefulness and appreciation in exchange } \\
\text { for the received service } \\
\text { e.g. "Saying thank you" }\end{array}$ \\
\hline Loyalty & 58 & 10 & $\begin{array}{l}\text { Customer visits the same FLE over a period of time. } \\
\text { e.g. "Standing in line to receive the service from a particular } \\
\text { employee when others are available" }\end{array}$ \\
\hline $\begin{array}{l}\text { Sensory } \\
\text { Expressiveness }\end{array}$ & 52 & 25 & $\begin{array}{l}\text { Customer displays positive body posture, facial expression, tone of } \\
\text { voice, etc. when communicating with the FLE. } \\
\text { e.g. "Smiling, maintaining eye contact" }\end{array}$ \\
\hline
\end{tabular}


Table 4: Overview of consequences for customers

\begin{tabular}{|c|c|c|}
\hline $\begin{array}{l}\text { Name of } \\
\text { consequences }\end{array}$ & $\begin{array}{l}\text { Number of } \\
\text { times } \\
\text { mentioned by } \\
\text { customers } \\
\text { (in ladders) }\end{array}$ & Description \\
\hline Feeling Altruistic & 76 & $\begin{array}{l}\text { Customer experiences empathy and a desire to help others coupled } \\
\text { with a lack of selfishness. } \\
\text { e.g. "Doing the good deed of the day" }\end{array}$ \\
\hline Belongingness & 16 & $\begin{array}{l}\text { Customer feels associated and part of a group. } \\
\text { e.g. "Feeling associated with the service /brand /fanclub } \\
\text { /organization" }\end{array}$ \\
\hline $\begin{array}{l}\text { Enhance Self- } \\
\text { image }\end{array}$ & 28 & $\begin{array}{l}\text { Customer self-image (or self-evaluation) is boosted. } \\
\text { e.g. "Feeling likeable, feeling proud after expressing positive } \\
\text { feedback" }\end{array}$ \\
\hline $\begin{array}{l}\text { Feeling } \\
\text { Comfortable }\end{array}$ & 67 & $\begin{array}{l}\text { Customer feels comfortable, satisfied, and content. } \\
\text { e.g. "Feeling calm and relaxed after giving positive feedback" }\end{array}$ \\
\hline $\begin{array}{l}\text { Feeling } \\
\text { Enthusiastic }\end{array}$ & 70 & $\begin{array}{l}\text { Customer experiences positive emotions and mood, feels } \\
\text { enthusiastic and excited. } \\
\text { e.g. "Feeling positively charged" }\end{array}$ \\
\hline $\begin{array}{l}\text { Feeling in } \\
\text { Control }\end{array}$ & 32 & $\begin{array}{l}\text { Customer feels in control of what he/she is doing and saying. } \\
\text { e.g. "Feeling powerful"" }\end{array}$ \\
\hline $\begin{array}{l}\text { Preferential } \\
\text { Treatment }\end{array}$ & 18 & $\begin{array}{l}\text { Customer gets preferential treatment in the form of tangible and } \\
\text { intangible benefits. } \\
\text { e.g. "Getting more attention from the FLE or getting a } \\
\text { complimentary free service" }\end{array}$ \\
\hline $\begin{array}{l}\text { Raised } \\
\text { Expectations }\end{array}$ & 9 & $\begin{array}{l}\text { Customer is yearning for even better service in the future } \\
\text { e.g. "Expecting better service after giving positive feedback" }\end{array}$ \\
\hline $\begin{array}{l}\text { Reduced } \\
\text { Uncertainty }\end{array}$ & 20 & $\begin{array}{l}\text { Customer uncertainty about the service is reduced. } \\
\text { e.g. "Feeling more confident about the purchase after expressing } \\
\text { positive feedback" }\end{array}$ \\
\hline Relationship & 75 & $\begin{array}{l}\text { Customer builds a relationship with the employee. } \\
\text { e.g. "As a result of PCF, we become closer to each other" }\end{array}$ \\
\hline Spillover & 7 & $\begin{array}{l}\text { PCF will affect customer's other aspects of life beyond the } \\
\text { particular service encounter (extended impact) } \\
\text { e.g. "Treating family and friends better" }\end{array}$ \\
\hline
\end{tabular}


Table 5: Overview of consequences for FLEs 
Table 6: Overview of values

\begin{tabular}{|c|c|c|c|}
\hline Name of value & $\begin{array}{c}\text { Number of } \\
\text { times } \\
\text { mentioned by } \\
\text { customers } \\
\text { (in ladders) }\end{array}$ & $\begin{array}{l}\text { Number of } \\
\text { times } \\
\text { mentioned } \\
\text { by FLEs } \\
\text { (in ladders) }\end{array}$ & $\begin{array}{c}\text { Description * } \\
* \text { Definitions from Shwartz }(1994, p .22)\end{array}$ \\
\hline Achievement & 36 & 38 & $\begin{array}{l}\text { "Personal success through demonstrating competence according to } \\
\text { social standards" }\end{array}$ \\
\hline Benevolence & 49 & 41 & $\begin{array}{l}\text { "Preservation and enhancement of the welfare of people with } \\
\text { whom one is in frequent personal contact" }\end{array}$ \\
\hline Conformity & 6 & 12 & $\begin{array}{l}\text { "Restraint of actions, inclinations, and impulses likely to upset or } \\
\text { harm others and violate social expectations or norms" }\end{array}$ \\
\hline Hedonism & 29 & 31 & "Pleasure and sensuous gratification for oneself" \\
\hline Power & 50 & 32 & $\begin{array}{l}\text { "Social status and prestige, control or dominance over people and } \\
\text { resources" }\end{array}$ \\
\hline Security & 51 & 49 & $\begin{array}{l}\text { "Safety, harmony, and stability of society, of relationships, and of } \\
\text { self" }\end{array}$ \\
\hline Self-Direction & 38 & 32 & "Independent thought and action-choosing, creating, exploring" \\
\hline Stimulation & 19 & 30 & "Excitement, novelty, and challenge in life" \\
\hline Tradition & 23 & 5 & $\begin{array}{l}\text { "Respect, commitment, and acceptance of the customs and ideas } \\
\text { that traditional culture or religion provide" }\end{array}$ \\
\hline Universalism & 56 & 28 & $\begin{array}{l}\text { "Understanding, appreciation, tolerance, and protection for the } \\
\text { welfare of all people and for nature" }\end{array}$ \\
\hline
\end{tabular}




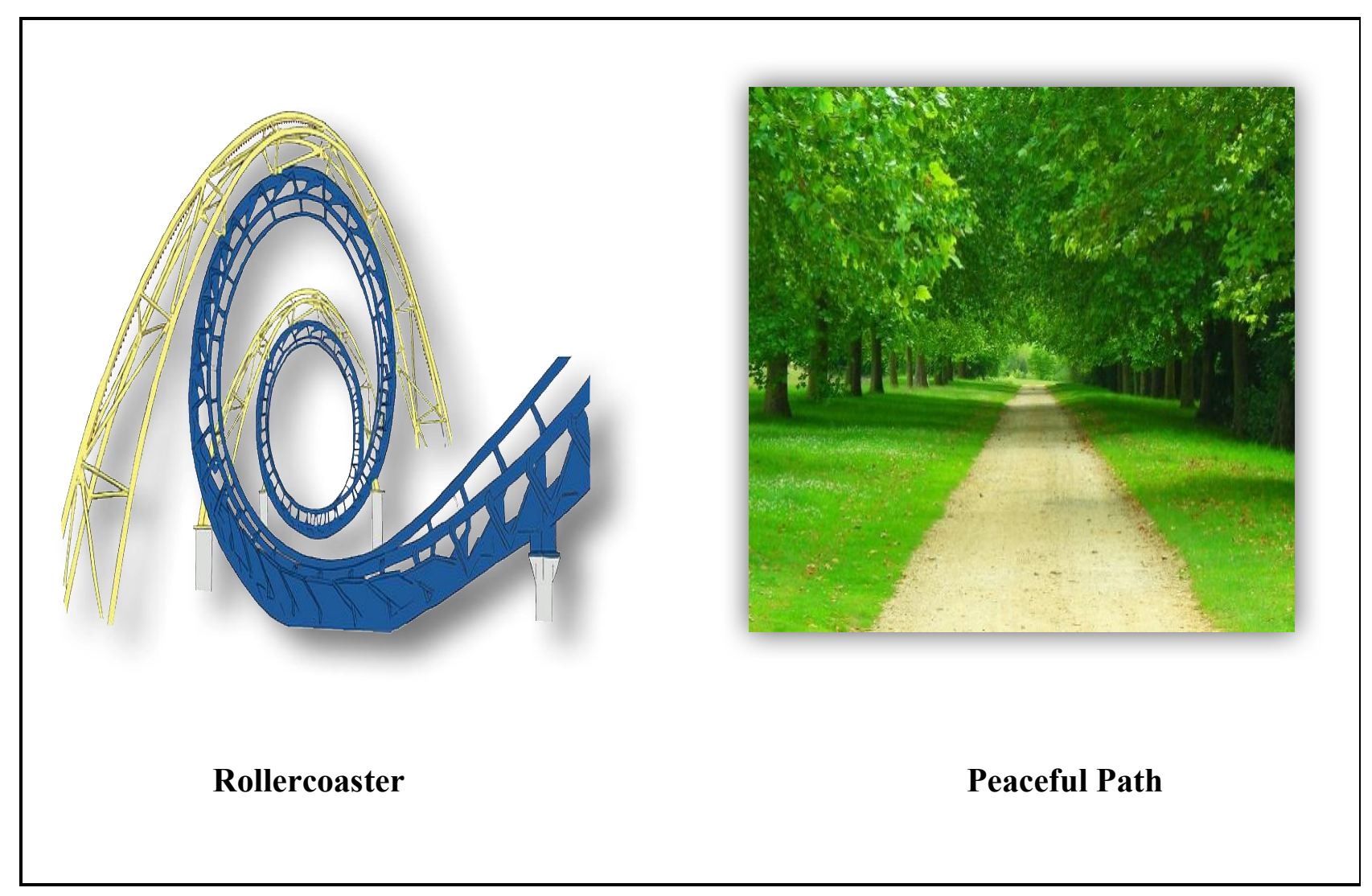


Page 49 of 50 Figure 2:

Customer

perception of

PCF attributes,

consequences,

and values.

Journal of Services Marketing

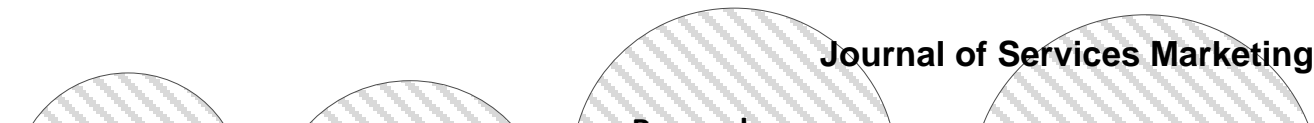

Stimulation

$\mathrm{N}=8$ Benevolence

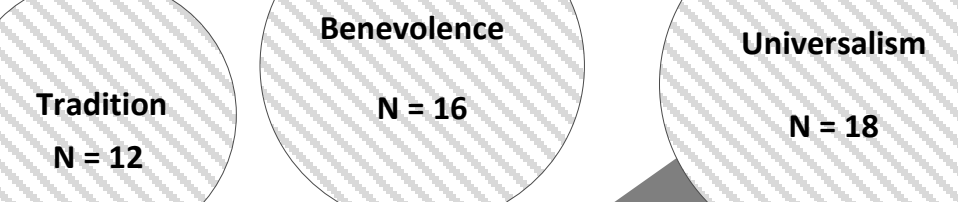

$\mathbf{N}=\mathbf{2 0}$

Power

$\mathrm{N}=12$

N $1+16$

$N=15$

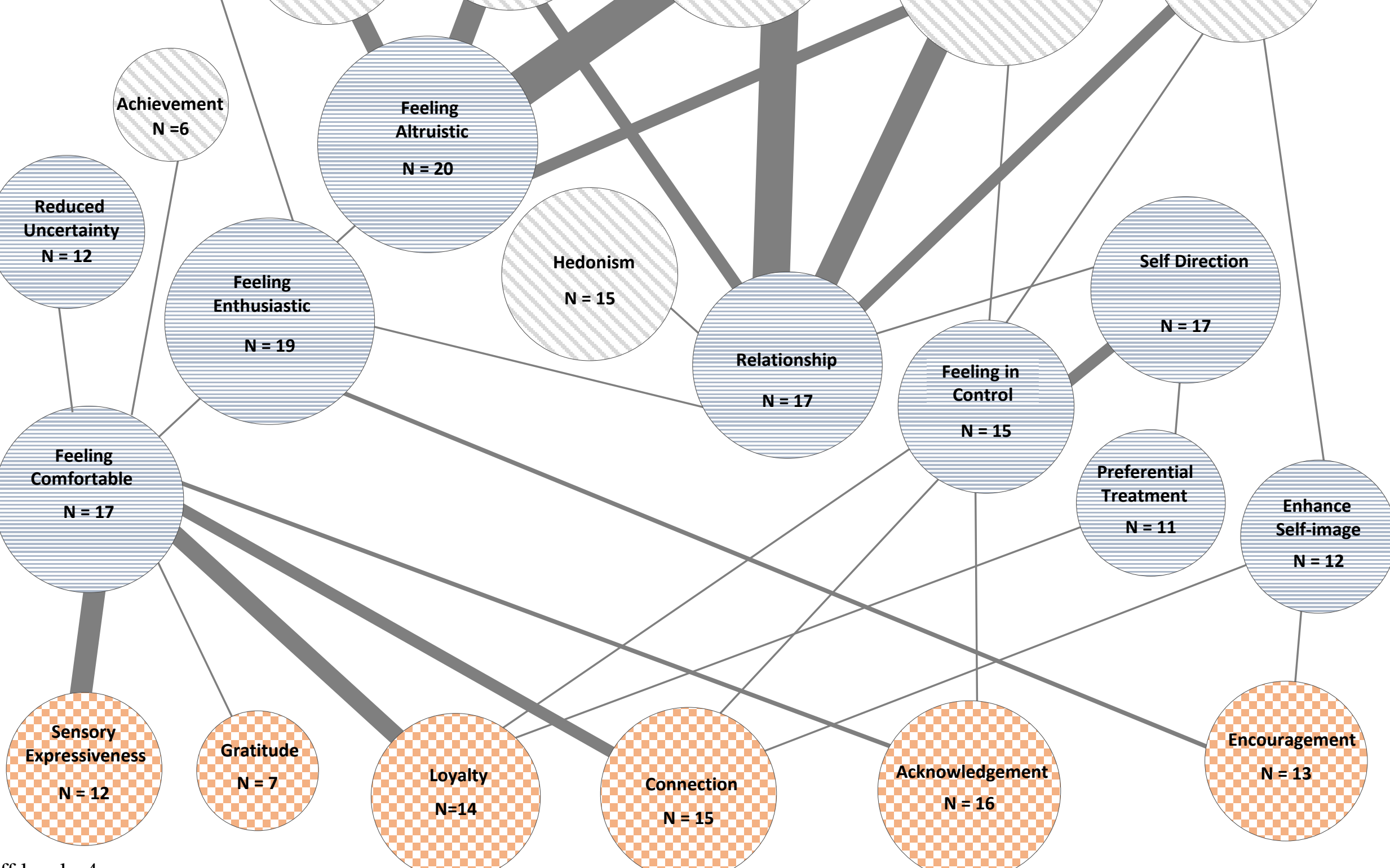

Note: Cut-off level= 4 
perception of

PCF attributes,

consequences,

and values.
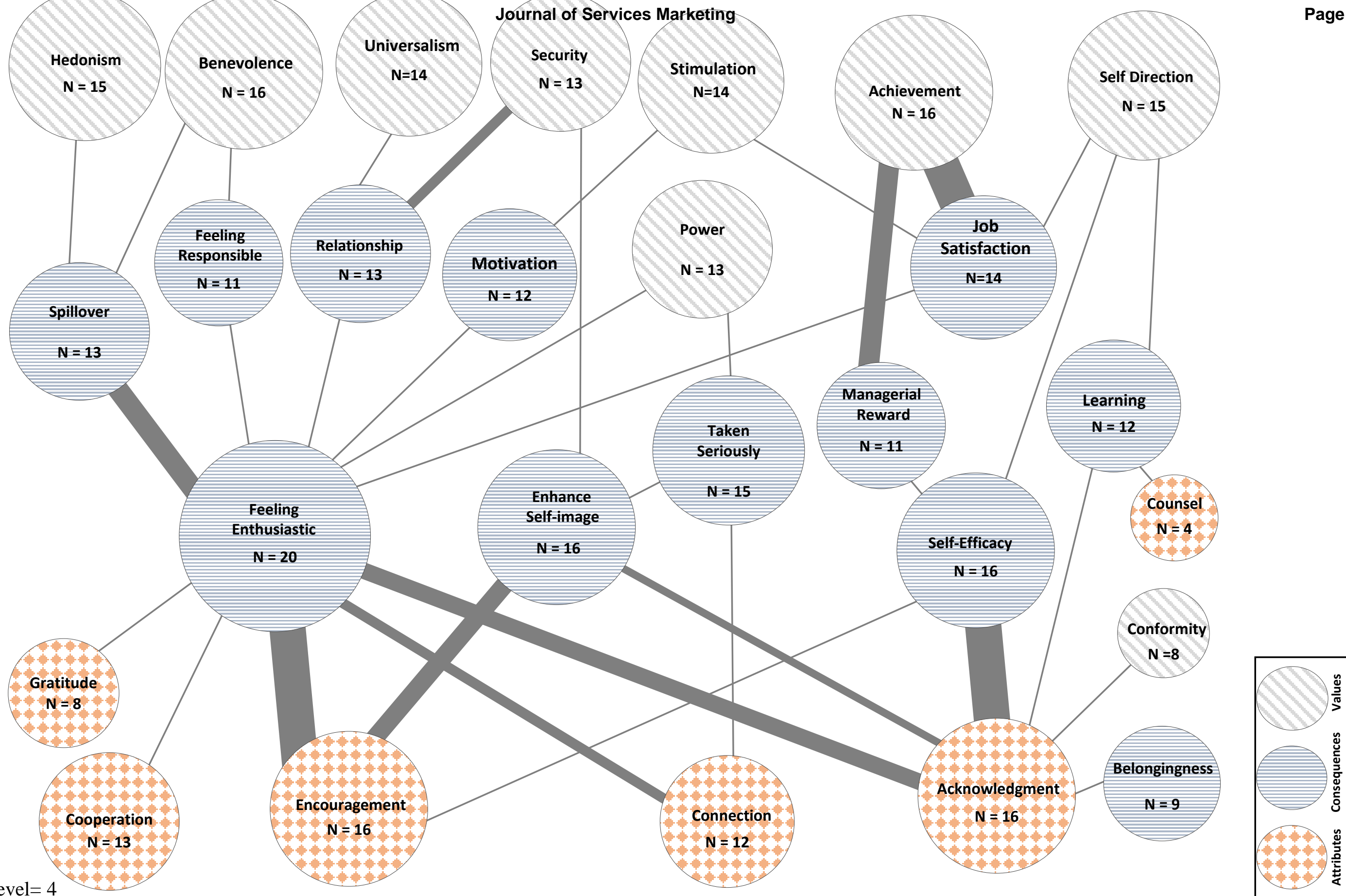

Note: Cut-off level= 